\title{
PVTx measurements of mixed clathrate hydrates in batch conditions under different crystallization rates: influence on equilibrium
}

\author{
Maghsoodloo Babakhani S., , Bouillot B., Douzet J., Ho-Van S., Herri J.M. \\ Ecole des Mines de Saint-Etienne, SPIN, CNRS 5307, LGF, F-42023 Saint-Etienne, France \\ * Corresponding author: saheb.m@emse.fr
}

\begin{abstract}
Notwithstanding the numerous studies about classical temperature and pressure equilibrium of mixed gas hydrates, few provide hydrate composition and volume at local and final equilibrium under batch conditions. Therefore, required new phase equilibrium data for mixed gas hydrates including $\mathrm{CO}_{2}-\mathrm{C}_{3} \mathrm{H}_{8}, \mathrm{C}_{2} \mathrm{H}_{6}-\mathrm{nC}_{4} \mathrm{H}_{10}, \mathrm{CH}_{4}-\mathrm{nC}_{4} \mathrm{H}_{10}, \mathrm{CO}_{2}-\mathrm{C}_{2} \mathrm{H}_{6}-\mathrm{C}_{3} \mathrm{H}_{8}, \mathrm{CH}_{4}-\mathrm{C}_{2} \mathrm{H}_{6}-\mathrm{nC}_{4} \mathrm{H}_{10}$ and $\mathrm{CH}_{4}$ $\mathrm{C}_{2} \mathrm{H}_{6}-\mathrm{C}_{3} \mathrm{H}_{8}-\mathrm{nC}_{4} \mathrm{H}_{10}$ are presented in this paper. Moreover, results contain hydrate phase properties such as hydrate volume and density, storage capacity, water conversion and guest composition in all phases (vapor, liquid and hydrate). Importantly, effect of crystallization rate on final state has been evaluated. Finally the experimental results were compared to the thermodynamic model of van der Waals and Platteeuw to investigate kinetic effects.

Experimental results show that equilibrium pressures at final state are dissimilar with respect to the crystallization rate. Furthermore, the hydrate volume formed at slow crystallization rate is noticeably lower than at quick. Noticeably, storage capacity in the case of slow crystallization is higher which could be crucial for industry. Also, the guest composition in hydrate phase at final state differs.

Enclathration of heavier molecules is more significant at slow crystallization rate, and the hydrate phase seems to be more homogeneous according to the thermodynamic study. Indeed, modeling results, that assume the hydrate phase to be homogeneous in composition, show better agreement with the slow crystallization results for both equilibrium pressure and guest distribution in hydrate phase. This elucidates that, at quick crystallization rate, thermodynamic equilibrium cannot be reached.
\end{abstract}

In conclusion, how kinetics influence the design of clathrate hydrate based industrial applications such as energy storage and transportation, carbon capture sequestration etc. are demonstrated.

Keywords: clathrate hydrates, phase equilibria, crystallization, thermodynamics, modeling, nonequilibrium

\section{Introduction}


Gas hydrates are crystalline solids that contain gas molecules in its molecular cages. Depending on the size and nature of the gases, there are three different well-known structures, cubic I, cubic II and hexagonal $\mathrm{H}$ [1].

There have been numerous studies about gas hydrates over the past decades because they represent critical pipeline blockage risk for the oil and gas industries as well as present severe safety and environmental hazards [2-5]. Moreover, an enormous amount of methane stored in the form of hydrates in permafrost and deep-sea deposits that theoretically offer a source of energy [6-9]. Additionally, there are several technological applications under development for gas hydrates such as natural gas storage and transportation, separation processes and water desalination [10-15]. Hence, more experimental data and consequently extended modeling approaches are needed to achieve a better fundamental understanding of the thermodynamics and crystallization mechanisms of gas hydrates.

A considerable body of research on the clathrate hydrates in the past studied the characterizations and thermodynamic conditions of gas hydrates by different experimental procedures and apparatuses. They have already been reviewed by Sloan and Koh [1] and Khan et al [16]. Nevertheless, there still exist a few important factors that rest unexplored due to measurement difficulties or experimental limitations of that time. Some like guest composition in hydrate phase and volume of hydrate are now of great importance. They play vital roles in applications which can accurately determining the quantity of gas hydrate during and at the end of crystallization is essential [4].

To clarify, several studies that deal with natural gas hydrates should be mentioned. Ng [17] measured the hydrate composition for six gas mixtures including methane, ethane, propane, isobutane, $\mathrm{n}$-butane and carbon dioxide. The author used n-pentane as a tracer in his experiments to determine the guest composition in hydrate phase. Then, he modeled the hydrate composition results by van der Waals and Platteeuw approach and concluded, with some exceptions, that the model was capable of predicting hydrate composition. Kawasaki et al. [18] studied the guest content in hydrate phase from a gas mixture of methane, ethane, propane and iso-butane. Their procedure was based on removing the gas inside the reactor and dissociating the hydrate to measure the hydrate composition at two different temperatures, 1 and $3^{\circ} \mathrm{C}$. The authors stated that all i-butane molecules concentrate in the hydrate phase regardless of the temperature. Sum et al. [19] utilized Raman spectrometry to study guest distribution in hydrate phase for $\mathrm{CH}_{4}-\mathrm{CO}_{2}$ binary mixture. Subramanian et al. [20,21] investigated the structural transition and hydrate composition of methane-ethane mixture based on Raman spectrometric and ${ }^{13} \mathrm{C}$ NMR measurements at six different vapor compositions. They reported that the structure of the mixed hydrates of methaneethane could change depending on the vapor composition.

Furthermore, concerns have been raised about the kinetic effects on clathrate hydrates formation and composition. Kvamme et al. [22] reported that mixed gas hydrates might not be theoretically reached at equilibrium by reassessing the Gibbs phase rule and the laws of thermodynamics. 
According to their investigations based on coupling the classical thermodynamic and molecular dynamics simulations, they stated that crystallization occurs not only in the bulk, but also at interfaces in the system or gas phase. Consequently, the driving force could be different due to diverging chemical potentials. Therefore, the Gibbs phase rule could over-determine the thermodynamic equilibrium without considering existence of any unforeseen phases.

Before going any further, let us state that thermodynamic equilibrium is the most stable state, the one that minimizes free energy of the system. Therefore, we consider that the system can reach an equilibrium point (no longer any change in state parameters), without being at thermodynamic equilibrium, as stated by Kvamme et al. Thus, it is metastable.

Some evidence shows how a metastable system could evolve toward a most stable state, or stay as it is. For instance, there are several indications of structural transition or co-existence of different structures during the crystallization of mixed gas hydrates. Subramanian et al. [20,21] and Uchida et al. [23] reported structural transition from sI to sII for methane-ethane mixture under certain range of vapor compositions. Schicks and Ripmeester [24] observed both sI and sII methane hydrate under moderate conditions. In addition, Herri et al. [25] and Peytavi et al. [26] experimentally investigated that the mass transfer limitation from gas to aqueous solution could hinder the crystallization process. Therefore, the guest composition in liquid phase appears mainly driven by kinetics. Hence, guest distribution in the hydrate phase should be affected during crystal growth. Murphy and Roberts [27] studied the fluid inclusion in $\mathrm{CO}_{2}$-rich gases and reported that there was not a single homogenous equilibrium clathrate composition. In fact, clathrates may form in different phases in the system with different compositions. Finally, they concluded that clathrate composition does not change quickly after crystallization. Salamatin et al. [28] studied mathematically the gas diffusion during gas replacement process by "hole-incage-wall" diffusive mechanism. They showed that gas exchange could be started by a rapid crystallization of a hydrate layer on the hydrate surface and then it can be continued by a much slower permeation process. Molecular dynamics simulation also support the idea that the hydrate structure that forms is not necessarily the most stable one, but the one that show the highest growth rate [29-33]. According to these studies, the question then arises, "Is thermodynamic equilibrium reached in short term processes?"

Our previous investigations on mixed hydrates showed this non-equilibrium phenomenon while comparing different crystallization rates [34,35]. Some of these experiments have been simulated with a "non-equilibrium flash model" with some success [36].

The objective of this work is to investigate other systems: $\mathrm{CO}_{2}-\mathrm{C}_{3} \mathrm{H}_{8}, \mathrm{C}_{2} \mathrm{H}_{6}-\mathrm{nC}_{4} \mathrm{H}_{10}, \mathrm{CH}_{4}-\mathrm{nC}_{4} \mathrm{H}_{10}$, ternary mixtures $\mathrm{CO}_{2}-\mathrm{C}_{2} \mathrm{H}_{6}-\mathrm{C}_{3} \mathrm{H}_{8}, \mathrm{CH}_{4}-\mathrm{C}_{2} \mathrm{H}_{6}-\mathrm{nC}_{4} \mathrm{H}_{10}$ and quaternary mixture $\mathrm{CH}_{4}-\mathrm{C}_{2} \mathrm{H}_{6}-\mathrm{C}_{3} \mathrm{H}_{8}-$ $\mathrm{nC}_{4} \mathrm{H}_{10}$. As before, different crystallization rates were applied in order to better understand the role of kinetics in mixed hydrate crystallization. The results obtained provide detailed information about temperature, pressure, guest composition in all phases (gas, liquid and hydrate) and hydrate volume. Only stable states, where state variables do not change with time, are 
considered. Therefore, time is not a relevant variable in this study. The different ''equilibrium states" reached are then examined and discussed. Additionally, experimental results are compared to the classical van der Waals and Platteeuw model.

\section{Materials and procedures}

\subsection{Materials}

Gases $\mathrm{CO}_{2}, \mathrm{CH}_{4}, \mathrm{C}_{2} \mathrm{H}_{6}, \mathrm{C}_{3} \mathrm{H}_{8}$ and $\mathrm{n}-\mathrm{C}_{4} \mathrm{H}_{10}$ were provided by Air Products. Gas mixtures were prepared by injection of pure gases (from the less volatile to more volatile) and weighting the bottle after each injection. The bottle composition was calculated by the mass of each gas.

Deionized water was obtained through a water purifier from a cleansing system "Millipore". This system is equipped with a cartridge "Milli-Q®-AdvantageA10" which lowers the conductivity of the water to $0.055 \mathrm{\mu Scm}^{-1}$. The total organic carbon content was less than $5 \mathrm{ppb}$. Moreover, about $10 \mathrm{ppm}$ of lithium was used in our experiments as a liquid tracer. The lithium solution was purchased from Merck. Since lithium does not participate in hydrate formation and also remains in solution, the volume of water converted to hydrate can be calculated by the concentration of lithium in the remaining liquid. Helium was also used as a carrier gas for chromatography analyses. This is supplied by Air Product. The materials used in this study are listed by details in Table 1.

Table 1. Materials used in this study

\begin{tabular}{|l|l|l|}
\hline \multicolumn{1}{|c|}{ Component } & \multicolumn{1}{c|}{ Supplier } & \multicolumn{1}{c|}{ Purity grade } \\
\hline Carbon dioxide & Air products & mole fraction 0.99999 \\
\hline Methane & Air products & mole fraction 0.9995 \\
\hline Ethane & Air products & mole fraction 0.995 \\
\hline Propane & Air products & mole fraction 0.9995 \\
\hline Butane & Air products & mole fraction 0.9995 \\
\hline Helium & Air products & mole fraction 0.99999 \\
\hline $\mathrm{Li}^{+}$Tracer & Merck & $\begin{array}{l}1001 \pm 5 \mathrm{mgdm}^{-3} \mathrm{Li}^{+} \\
\text {LiNO } \text { in } 0.5 \mathrm{moldm}^{-3} \mathrm{HNO}_{3} \text { aqueous solution }\end{array}$ \\
\hline Water & $\begin{array}{l}\text { Milli-Q®- } \\
\text { AdvantageA10 }\end{array}$ & $\begin{array}{l}\text { Organic content }<5 \mathrm{ppb} \\
\text { Salinity: conductivity of } \sigma=0.055 \mu \mathrm{Scm}^{-1}\end{array}$ \\
\hline
\end{tabular}

\subsection{Experimental set-up}

A schematic of the experimental set-up is presented in Figure 1. Two batch reactors with the same characteristics and specifications were utilized (except the inner volume, the first is $2.36 \mathrm{~L}$ and the second $2.23 \mathrm{~L}$ ). Both are equipped with two sapphire windows which allow direct observation and they can resist pressure up to 100 bar. Agitation systems include vertical stirrers with two sets of blades. The top set of blades is in the gas phase and the bottom set in liquid. This 
allows stirring the contents up to $25 \mathrm{~Hz}(1500 \mathrm{rpm})$ to increase the surface contact. The autoclave is surrounded by a cooling jacket and the temperature is controlled by a cryostat LAUDA RC6 $\mathrm{CS}$ ranging from -15 to $50^{\circ} \mathrm{C}$. Temperature inside the reactor is monitored by two Pt100 probes (temperature accuracy $\pm 0.2^{\circ} \mathrm{C}$ ), for gas and liquid phases. The pressure is also measured by a pressure sensor in the range $0-10 \mathrm{MPa}$ (pressure accuracy $\pm 0.01 \mathrm{MPa}$ ). The liquid is injected in the reactor under pressure (1 to $10 \mathrm{MPa}$ ) by using a HPLC pump (KNAUER P4.1S). An online ROLSI sampler is mounted on the reactor for sampling the gas and subsequently sending it into a gas chromatograph (GC Varian model 38002) equipped with a TCD detector and two columns PoraBOND Q and CP-Molsieve. Peak integration is possible with software provided by Varian Galaxie. The liquid samples throughout the experiments are taken by a mechanical valve and a capillary tube which is located in the liquid phase. The samples are then analyzed by ion chromatography system Dionex ICS-5000 ${ }^{+}$. Data acquisition is controlled on a personal computer running Labview.

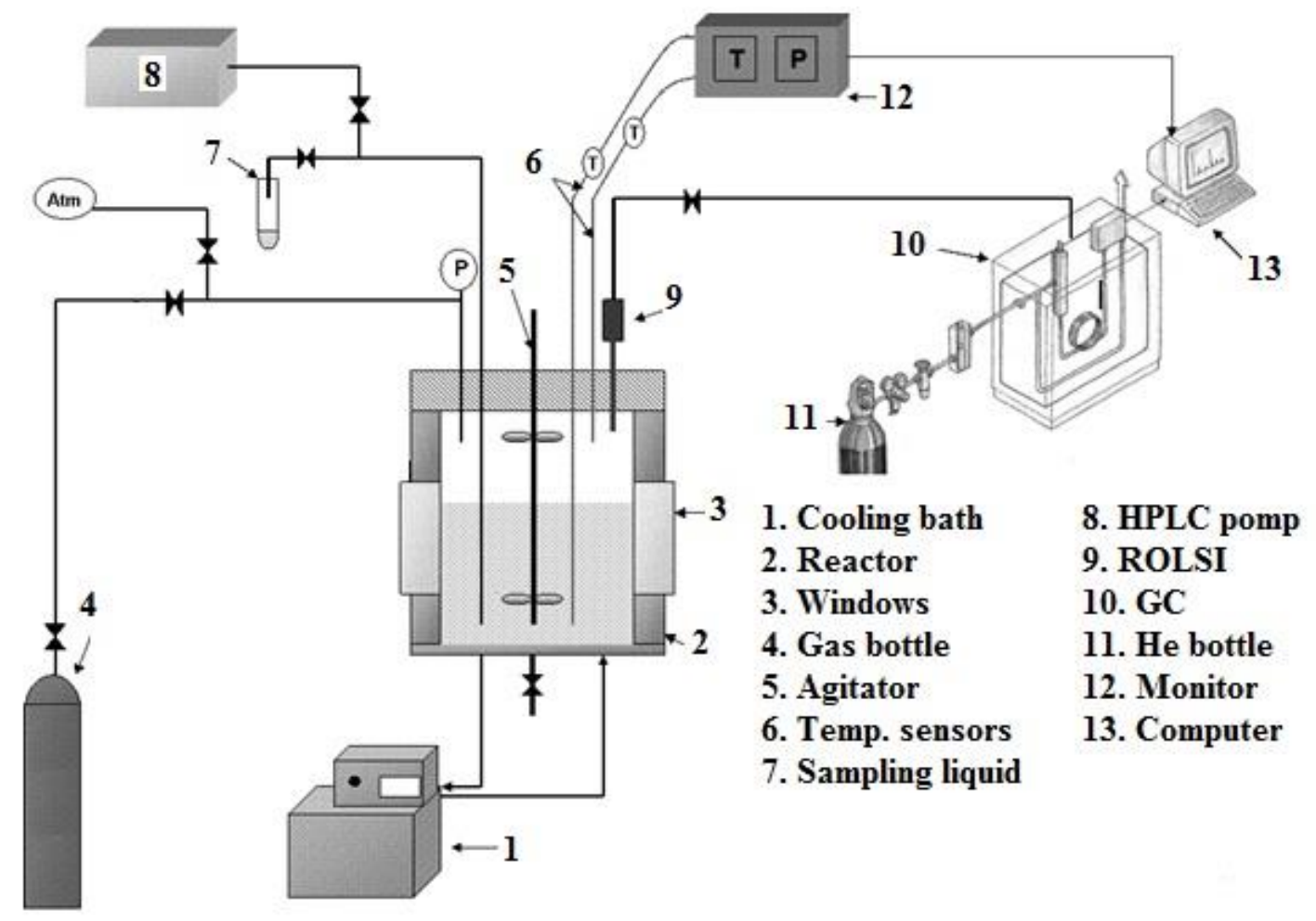

Figure 1. Schematic of experimental set-up

\subsection{Experimental procedures}

To evaluate effects of crystallization rate on the equilibrium condition at final state, both quick and slow crystallization were investigated. Quick crystallization evaluates the formation and dissociation of mixed gas hydrates at high initial supersaturation. Whereas at slow crystallization the aim is to neglect the kinetic effects as much possible. This means that we could be closer to the thermodynamic equilibrium condition which usually occurs in steady state processes. 


\subsubsection{Quick crystallization process}

First, the reactor is filled by nitrogen up to $50 \mathrm{bar}$ in order to check the cell for the leakage. The pressure is monitored between 24 to 48 hours to ensure that there is no pressure drop. The cell is then evacuated by a vacuum pump. Then, pressure is raised by injecting the aforementioned gas mixtures: $\mathrm{CO}_{2}-\mathrm{C}_{3} \mathrm{H}_{8}, \mathrm{C}_{2} \mathrm{H}_{6}-\mathrm{nC}_{4} \mathrm{H}_{10}, \mathrm{CH}_{4}-\mathrm{nC}_{4} \mathrm{H}_{10}$, ternary mixtures $\mathrm{CO}_{2}-\mathrm{C}_{2} \mathrm{H}_{6}-\mathrm{C}_{3} \mathrm{H}_{8}, \mathrm{CH}_{4}-\mathrm{C}_{2} \mathrm{H}_{6}$ $\mathrm{nC}_{4} \mathrm{H}_{10}$ and quaternary mixture $\mathrm{CH}_{4}-\mathrm{C}_{2} \mathrm{H}_{6}-\mathrm{C}_{3} \mathrm{H}_{8}-\mathrm{nC}_{4} \mathrm{H}_{10}$. Several gas samples are taken and the molar composition of gas mixture is analyzed by GC. About $800-1000 \mathrm{~mL}$ of water (including 10 ppm $\mathrm{Li}^{+}$) is then inserted into the cell via the HPLC pump. The temperature is set to $0-1^{\circ} \mathrm{C}$ and the agitation is started with about $6.6 \mathrm{~Hz}(400 \mathrm{rpm})$ rate. After a short period, about a day, the crystallization starts and as a result of hydrate formation, a pressure drop is observed. Then, we wait for the equilibrium (the stability of pressure and temperature). At this point, we take gas and liquid sample for analyses. The dissociation process is then initiated. The temperature is increased step by step. At each equilibrium step, gas and liquid samples are taken. This process is repeated until there is no more hydrate in the cell. The whole procedure takes about 25 days for each mixture.

\subsubsection{Slow crystallization process}

At the end of quick crystallization process, the amount of water samples taken is measured. The same amount of water is then replaced into the reactor to have almost the same initial pressure and temperature conditions. Pressure, temperature and guest compositions are analyzed to assure that the same initial conditions are going to be considered. At this point, slow crystallization procedure starts. However, instead of decreasing quickly the temperature is decreased very slowly $\left(0.3^{\circ} \mathrm{C}\right.$ per 12 hours and we wait to reach equilibrium at each temperature drop iteration). Gas and liquid samples are taken during and at the end of crystallization. In this case, the process takes about 60 days for each mixture as opposed to 30 .

\subsection{Material balance}

At starting condition, where there is only gas in the reactor, the amount of gas can be calculated as follows:

$n_{j}^{0}=\frac{P V^{R}}{Z\left(P, T, y_{j}^{0}\right) R T}$

where $j$ is guest molecule, $O$ indicates the initial condition, $V^{R}$ is volume of reactor, $Z$ is compressibility factor, $T$ and $P$ stand for the gas temperature and pressure, respectively. The molar compositions of guest molecules at initial condition $\left(y_{j}^{0}\right)$ were obtained from results of gas chromatography.

Figure 2 presents the mass balance calculation at equilibrium conditions. The volume of water $\left(V^{L}\right)$ was calculated based on the concentrations of lithium at initial and equilibrium conditions ([Li+ $\left.\left.{ }^{+}\right]\right)$. According to the volume of water at equilibrium, and also Henry's law, the solubility of 
the guest molecules in water, $n_{j}^{L}$ was then calculated (the second line in Figure 2). In the equations, $\rho_{w}^{0}$ and $M_{w}$ stand for the density and molecular weight of water, respectively, $\varphi_{j}^{G}$ fugacity coefficient of gas $j$ and $K_{H, j}^{\infty}$ is Henry's constant. Table 2 shows the A and B for several gases which have been used in the present work to calculate Henry's constant.

(2)

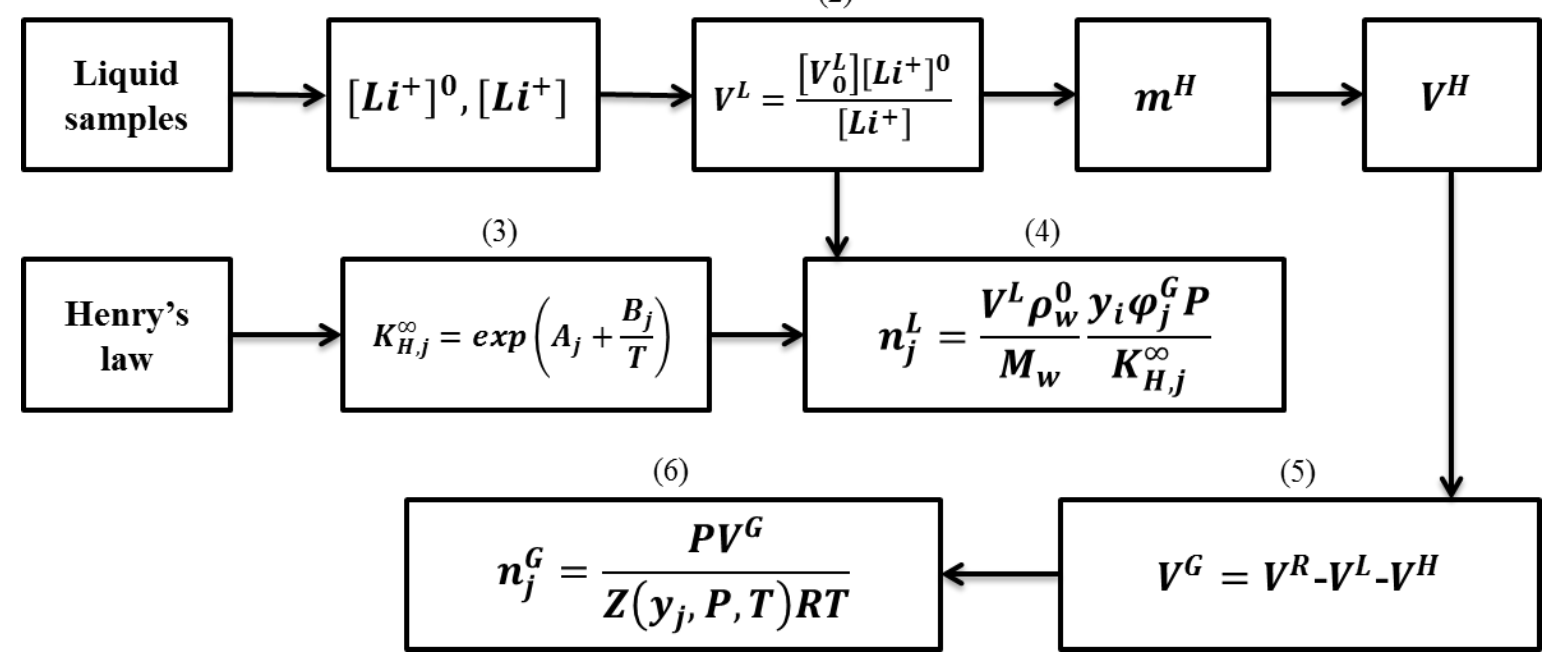

Figure 2. Mass balance calculations at equilibrium conditions

Table 2. The values of A and B for calculating the Henry's constants [37]

\begin{tabular}{|l|c|c|}
\hline $\mathbf{G a s}$ & $\boldsymbol{A}^{*}$ & $\boldsymbol{B}^{*}(\mathbf{K})$ \\
\hline $\mathbf{C O}_{\mathbf{2}}$ & 14.283146 & -2050.3269 \\
\hline $\mathbf{C H}_{\mathbf{4}}$ & 15.872677 & -1559.0631 \\
\hline $\mathbf{C}_{\mathbf{2}} \mathbf{H}_{\mathbf{6}}$ & 18.400368 & -2410.4807 \\
\hline $\mathbf{C}_{\mathbf{3}} \mathbf{H}_{\mathbf{8}}$ & 20.958631 & -3109.3918 \\
\hline $\mathbf{n C}_{\mathbf{4}} \mathbf{H}_{\mathbf{1 0}}$ & 22.150557 & -3407.2181 \\
\hline \multicolumn{2}{|l}{$\mathrm{A}$ and B are Henry's constants } \\
\hline
\end{tabular}

By the mass of water converted to hydrate, the volume of hydrate was calculated based on theoretical density of structure I and II [1]. Then, volume of gas at equilibrium was obtained by subtracting the hydrate and liquid volumes from volume of reactor. Consequently, the mole number of guests in the gas phase was calculated with the equation 6 in Figure 2.

The amount of gas molecules in hydrate phase was calculated based on the mass balance at initial state and amount of guest in gas and liquid phases as following:

$n_{j}^{H}=n_{j}^{0}-n_{j}^{L}-n_{j}^{G}$

where $n$ is mole number, $L, H$ and $G$ stand for the liquid, hydrate and gas phases, respectively. 
The hydrate density was then calculated based on the mass of converted water plus mass of encaged guest molecules divided per volume of hydrate.

\subsection{Experimental and instrumental uncertainties and assumptions}

Determining uncertainties in any experimental procedures is essential. In this section, a brief description of sampling influence as well as errors is presented. The different resources of instrumental errors as well as their calculations were explained in details in our previous works $[34,35,38]$. Standard uncertainties of all measured and derived quantities have been provided in Table 3 and the footnote of each table.

As aforementioned, each experiment of slow crystallization process takes about 60 days (for quick crystallization process is about 25 days). Hence, it is not practical to investigate the reproducibility of each mixture and procedure. Nonetheless, we replicated two experiments under the same conditions on $\mathrm{CH}_{4} / \mathrm{C}_{3} \mathrm{H}_{8}$ mixture in order to assess the quality of experimental data. The results showed that, at a desired temperature, the pressure difference was less than 0.2 bar. The discrepancy in guest composition in gas and hydrate phases were about 0.006 and 0.008 mole fraction, respectively. Thus, it could be an evidence to ascertain the quality of experimental data produced during the experimentation.

The amount of gas samples were only about a few $\mu \mathrm{m}^{3}$, so can be ignored. At each equilibrium state, about 1-2 mL of solution was sampled. Hence, the amount of solution inside the reactor was actualized at each step according to the mass of water and lithium samples taken.

Moreover, as the hydrate volume and composition were obtained by changes in lithium concentrations, it seems obvious that larger amounts of hydrate lead to more accurate calculations. As a result, mass balance calculations sometimes fail near the total dissociation point. Indeed, when calculating with very small amounts of hydrates, close to zero, measurement uncertainties can lead to a negative mass for the hydrate. On the other hand, at the final state of equilibrium, the results are precise and reliable.

Table 3. The experimental and instrumental uncertainties

\begin{tabular}{|l|l|l|}
\hline Parameter & Standard uncertainty & Source of uncertainty \\
\hline Temperature & $0.2^{\circ} \mathrm{C}$ & Instrumental \\
\hline Pressure & $0.1 \mathrm{bar}$ & Instrumental \\
\hline Volume of reactor & $0.001 \mathrm{~L}$ & Instrumental \\
\hline Mass of water & $0.1 \mathrm{~g}$ & Instrumental \\
\hline Guest composition in gas phase & 0.001 mole fraction & Instrumental \\
\hline $\begin{array}{l}\text { Guest composition in hydrate } \\
\text { composition }\end{array}$ & 0.003 mole fraction & Experimental \\
\hline Guest composition in liquid phase & 0.003 mole fraction & Experimental \\
\hline Hydrate volume & $0.4 \mathrm{~cm}^{3}$ & Experimental \\
\hline Hydration number & 0.5 & Experimental \\
\hline Hydrate density & $0.05 \mathrm{~g} / \mathrm{cm}^{3}$ & Experimental \\
\hline
\end{tabular}




\begin{tabular}{|l|l|l|}
\hline Storage capacity & $0.5 \mathrm{~V} / \mathrm{V}$ & Experimental \\
\hline Water conversion & 0.4 & Experimental \\
\hline Gas solubility in the liquid phase & $0.3 \mathrm{mmol} / \mathrm{L}$ & Experimental \\
\hline
\end{tabular}

\section{Modeling}

\subsection{Thermodynamic model}

Among the different methods of modeling phase equilibria of gas hydrates [39-43], the thermodynamic model of van der Waals and Platteeuw was coupled with Kihara interaction potential in the present study. Given the fact that the assumptions in the model are restrictive, but it could works for many cases to predict phase behavior of clathrate hydrates [44].

This method considers a hypothetical phase, called $\beta$, which corresponds to the empty cavities hydrate. Hence, thermodynamic equilibrium of gas hydrates is defined by the equality of difference between chemical potential of water in liquid and $\beta$ phase $\left(\Delta \mu_{W}^{L-\beta}\right)$ and the difference between chemical potential of water in hydrate phase and $\beta$ phase $\left(\Delta \mu_{W}^{H-\beta}\right)$ :

$\Delta \mu_{W}^{L-\beta}=\Delta \mu_{W}^{H-\beta}$

The left hand side of the equation 8 , can be calculated based on the Gibbs-Duhem equation (classical thermodynamics) as following:

$\Delta \mu_{W}^{L-\beta}=T \frac{\left.\Delta \mu_{W}^{L-\beta}\right|_{T^{0} P^{0}}}{T^{0}}+\left(b_{P, W}^{L-\beta} T^{0}-\left.\Delta C_{p, w}^{L-\beta}\right|_{P^{0} T^{0}}\right)-T \ln \frac{T}{T^{0}}+\frac{1}{2} b_{P, W}^{L-\beta} T\left(T-T^{0}\right)+\left(\left.\Delta h_{W, m}^{L-\beta}\right|_{P^{0} T^{0}}+\right.$
$\left.T^{0}\left(b_{P, W}^{L-\beta} T^{0}-\left.\Delta C_{p, W}^{L-\beta}\right|_{P^{0} T^{0}}\right)-\frac{1}{2} b_{P, W}^{L-\beta} T^{0^{2}}\right)\left(1-\frac{T}{T^{0}}\right)+\left.\Delta v_{W, m}^{L-\beta}\right|_{T^{0}}\left(P-P^{0}\right)-R T \ln x_{W}^{L}$

In this equation, $T^{0}=273.15 \mathrm{~K}$ and $P^{0}=0$ bar are the reference temperature and pressure. $x_{W}^{L}$ is the mole fraction of water in liquid phase. The other parameters and their values are in Table 4.

Table 4. Macroscopic and reference properties of hydrates

\begin{tabular}{|c|c|c|c|c|}
\hline Parameter & Unit & Structure I & Structure II & Reference \\
\hline$b_{P, W}^{L-\beta}$ & $\mathrm{J} /\left(\mathrm{mol} . \mathrm{K}^{-2}\right)$ & 0.141 & 0.141 & {$[1]$} \\
\hline$\left.\Delta C_{p, w}^{L-\beta}\right|_{P^{0} T^{0}}$ & $\mathrm{~J} /\left(\mathrm{mol} . \mathrm{K}^{-1}\right)$ & -38.12 & -38.12 & {$[1]$} \\
\hline$\left.\Delta v_{W, m}^{L-\beta}\right|_{T^{0}}$ & $10^{-6} \mathrm{~m}^{3} . \mathrm{mol}$ & 4.5959 & 4.99644 & {$[1]$} \\
\hline$\left.\Delta \mu_{W}^{L-\beta}\right|_{T^{0} P^{0}}$ & $\mathrm{~J} / \mathrm{mol}$ & 1287 & 1068 & {$[45]$} \\
\hline$\left.\Delta h_{W, m}^{I-\beta}\right|_{P^{0} T^{0}} ^{\mathrm{a}}$ & $\mathrm{J} / \mathrm{mol}$ & 931 & 764 & {$[45]$} \\
\hline$\left.\Delta h_{W, m}^{L-\beta}\right|_{P^{0} T^{0}}$ & $\mathrm{~J} / \mathrm{mol}$ & $\left.\Delta h_{W, m}^{L-\beta}\right|_{P^{0} T^{0}}-6011^{\mathrm{b}}$ & $\left.\Delta h_{W, m}^{L-\beta}\right|_{P^{0} T^{0}}-6011^{\mathrm{b}}$ & {$[45]$} \\
\hline
\end{tabular}


The right hand side of equation 8 can be expressed from statistical thermodynamics, based on the occupancy factor of molecule $j$ in cavity $i\left(\theta_{j}^{i}\right)$. To obtain the occupancy factor, requires calculating the fugacity of component $j(f j)$, and Langmuir constant of component $j$ in cavity $i$ $\left(C_{j}^{i}\right)$. The latter describes the potential interaction between the guest molecules and surrounding water molecules. $C_{j}^{i}$ can be stated by a spherical symmetrical potential (equation 13$) . w(r)$ is the interaction potential between the guest molecule and the cavity based on the distance between the gas and water molecules in the structure $(r)$. There are several models employed to calculate this parameter. However, Mc Koy and Sinanoglu recommended that Kihara potentials are a more precise approach to model $w(r)$ [46]. The whole procedure is presented in Figure 3.

(10)

$$
\Delta \mu_{W}^{H-\beta}=R T \sum_{i} v_{i} \ln \left(1-\sum_{j} \theta_{j}^{i}\right) \longrightarrow \theta_{j}^{i}=\frac{C_{j}^{i} f_{j}(T, P)}{1+\sum_{j} C_{j}^{i} f_{j}(T, P)}
$$

\section{(11)}

(12)

$$
\Delta \mu_{W}^{H-\beta}=R T \sum_{i} v_{i} \ln \left(1-\sum_{j} C_{j}^{i} f_{j}(T, P)\right)
$$

$$
\begin{gathered}
\begin{array}{c}
(14) \\
w(r)=2 z \varepsilon\left[\frac{\sigma^{12}}{R^{11} r}\left(\Delta^{10}+\frac{a}{R} \Delta^{11}\right)-\frac{\sigma^{6}}{R^{5} r}\left(\Delta^{4}+\frac{a}{R} \Delta^{5}\right)\right] \\
\downarrow \\
\Delta^{N}=\frac{1}{N}\left[\left(1-\frac{r}{R}-\frac{a}{R}\right)^{-N}-\left(1+\frac{r}{R}-\frac{a}{R}\right)^{-N}\right]
\end{array} \\
\hline
\end{gathered}
$$

$$
C_{j}^{i}=\frac{4 \pi}{k T} \int_{0}^{\infty} \exp \left(-\frac{w(r)}{k T}\right) r^{2} d r
$$

Figure 3. The calculation procedure of difference between chemical potential of water in hydrate phase and $\beta$ phase

All the thermodynamic modelling section has been implemented in our in-house software, GasHyDyn, which aids to predict hydrate composition as well as equilibrium pressure.

Any deviation errors of the thermodynamic model used from the experimental results for hydrate pressure and composition is evaluated by equations 16 and 17, respectively.

$A A D p \%=\frac{100}{N} \sum_{i}^{N}\left(\left|\frac{P_{i}^{e x p}-P_{i}^{\text {pre }}}{P_{i}^{\text {exp }}}\right|\right)$ 
$A A D c=\frac{1}{N} \sum_{i}^{N}\left(\left|x_{i}^{\text {exp }}-x_{i}^{\text {pre }}\right|\right)$

where $i$ is equilibrium point, $N$ stands for the total number of equilibrium points, $P$ indicates pressure, $x$ is guest composition in hydrate phase, exp and pre are experimental and predicted data. $A A D p$ and $A A D c$ indicate average absolute deviation for pressure and composition, respectively.

\subsection{Kihara potential}

In equation $14, \varepsilon$ corresponds to the maximum attractive potential and as to the Kihara parameters $\sigma$ and $a$ : $\sigma$ is the distance from the center of cavity at maximum attractive potential and $a$ the hard-core radius. Kihara parameters for each guest molecules are unique and they do not depend on the type of cavity. They are fitting parameters and are generally determined from hydrate equilibrium data for pure components. Table 3 presents the Kihara parameters for the gas molecules used in this study, based on the previous works.

Table 5. Kihara parameters of the gas molecules used in this paper

\begin{tabular}{|c|c|c|c|c|}
\hline Guest molecule & $a$ [47] & $\varepsilon / \kappa$ & $\sigma$ & Reference \\
\hline $\mathrm{CO}_{2}$ & 0.6805 & 178.21 & 2.873 & [48] \\
\hline $\mathrm{CH}_{4}$ & 0.3834 & 166.36 & 3.050 & [48] \\
\hline $\mathrm{C}_{2} \mathrm{H}_{6}$ & 0.5651 & 177.46 & 3.205 & [34] \\
\hline $\mathrm{C}_{3} \mathrm{H}_{8}$ & 0.6502 & 195.00 & 3.340 & [35] \\
\hline $\mathrm{nC}_{4} \mathrm{H}_{10}$ & 0.9379 & 209.00 & 2.912 & [47] \\
\hline
\end{tabular}

\subsection{Comments on the modeling}

In equation $14, z$ is the total number of water molecules per cavity (coordination number) and $R$ the free cavity radius. Their values were already measured by $x$-ray diffraction and informed by Sloan and Koh [1]. It should be noted that, the values of $z$ and $R$ do never change according to the type of guest molecules. Furthermore, the model supposes that there is only one guest molecule at each cavity and the guest molecules do not deform the cavities. The guest-guest interaction has been also neglected. In addition, it was assumed that the internal motion function of the guest molecules in the cavities is similar to an ideal gas. This means that the guest enclathration has no significant impacts on vibrational or electronic energies [1].

Moreover, several assumptions have been taken into account for the Langmuir adsorption analogy. First, the enclathration of guest molecules takes place at separate cavities on the crystal unit cell. Secondly, the energy of enclathration does not depend on the presence of the other molecules. Finally, the dissociation rate is only governed by the amount of guest molecules in the crystal unit cell [1]. 


\section{Results and discussion}

\subsection{Initial conditions}

As aforementioned, hydrate volume and composition were ignored by the researchers due to measurements difficulties. Therefore, there are few studies in the literature about these important parameters. In the present article, several mixed gas hydrates from $\mathrm{CO}_{2}-\mathrm{CH}_{4}-\mathrm{C}_{2} \mathrm{H}_{6}-\mathrm{C}_{3} \mathrm{H}_{8}-\mathrm{nC}_{4} \mathrm{H}_{10}$ have been studied involving equilibrium temperature and pressure, guest composition in all phases (gas, liquid and hydrate), hydrate volume, water conversion, hydrate density, hydration number and storage capacity. Furthermore, this work includes not only the investigation at final state, but also during the crystallization at non-equilibrium conditions as well. Additionally, the influence of the crystallization rate has been evaluated.

Table 6 presents the initial conditions of the experiments. As seen in the table, for all the mixtures, the initial conditions of quick and slow procedures were approximately similar.

Table 6. Initial conditions of the experiments

\begin{tabular}{|c|c|c|c|c|c|c|c|c|c|c|}
\hline \multirow{2}{*}{ Gas } & \multirow{2}{*}{$\begin{array}{c}\text { Type of } \\
\text { exp. }\end{array}$} & \multicolumn{5}{|c|}{ Feed molar composition } & \multirow{2}{*}{$\mathrm{V}_{\mathrm{R}}(\mathrm{L})$} & \multirow{2}{*}{ Water(g) } & \multirow{2}{*}{$\mathrm{T}_{\mathrm{i}}\left({ }^{\circ} \mathrm{C}\right)$} & \multirow{2}{*}{$P_{i}($ bar $)$} \\
\hline & & $\mathrm{CO}_{2}$ & $\mathrm{CH}_{4}$ & $\mathrm{C}_{2} \mathrm{H}_{6}$ & $\mathrm{C}_{3} \mathrm{H}_{8}$ & $\mathrm{nC}_{4} \mathrm{H}_{10}$ & & & & \\
\hline \multirow{2}{*}{1} & Quick & 0.956 & - & - & 0.044 & - & 2.36 & 1022.3 & 16.3 & 26.1 \\
\hline & Slow & 0.932 & - & - & 0.068 & - & 2.36 & 1023.0 & 16.3 & 26.1 \\
\hline \multirow{2}{*}{2} & Quick & - & - & 0.956 & - & 0.044 & 2.23 & 801.0 & 16.3 & 16.6 \\
\hline & Slow & - & - & 0.966 & - & 0.034 & 2.23 & 802.4 & 16.3 & 16.6 \\
\hline \multirow{2}{*}{3} & Quick & - & 0.959 & - & - & 0.041 & 2.36 & 801.8 & 16.0 & 16.5 \\
\hline & Slow & - & 0.960 & - & - & 0.040 & 2.36 & 803.9 & 16.0 & 16.5 \\
\hline \multirow{2}{*}{4} & Quick & - & 0.838 & 0.107 & - & 0.055 & 2.23 & 1000.2 & 16.7 & 18.5 \\
\hline & Slow & - & 0.840 & 0.107 & - & 0.053 & 2.23 & 1000.4 & 16.7 & 18.5 \\
\hline \multirow{2}{*}{5} & Quick & 0.385 & - & 0.403 & 0.212 & - & 2.36 & 1000.2 & 17.3 & 12.9 \\
\hline & Slow & 0.287 & - & 0.468 & 0.245 & - & 2.36 & 1001.2 & 17.3 & 12.9 \\
\hline 6 & Quick & - & 0.737 & 0.120 & 0.124 & 0.019 & 2.36 & 801.4 & 15.7 & 15.5 \\
\hline \multicolumn{2}{|c|}{$\begin{array}{c}\text { Standard } \\
\text { uncertainty }\end{array}$} & \multicolumn{5}{|c|}{0.001 mole fraction } & $0.001 \mathrm{~L}$ & $0.1 \mathrm{~g}$ & $0.2^{\circ} \mathrm{C}$ & 0.1 bar \\
\hline
\end{tabular}

\subsection{Pressure and temperature evolution during the slow and quick crystallizations}

A detailed analysis of the two experimental procedures will be presented now. Figure 4 illustrates the changes of temperature and pressure during the quick crystallization for ethane-butane mixture. The experiment was started at initial point (A). The solution was then rapidly cooled down near $1{ }^{\circ} \mathrm{C}$ and after a while (depending on the gas mixture), crystallization started (B). Due to hydrate formation, the pressure decreased. We waited until the end of crystallization, point $\mathrm{C}$ (where there were no longer changes in temperature and pressure for 48 hours). Once gas hydrate formation was completed, the temperature was increased incrementally and every two days, gas and liquid samples were taken for analysis. The dissociation process was repeated until the 
dissociation curve meets the cooling line (D). Then, the amount of sampled water was then reinjected into the reactor. Temperature was reset to have the same initial conditions.

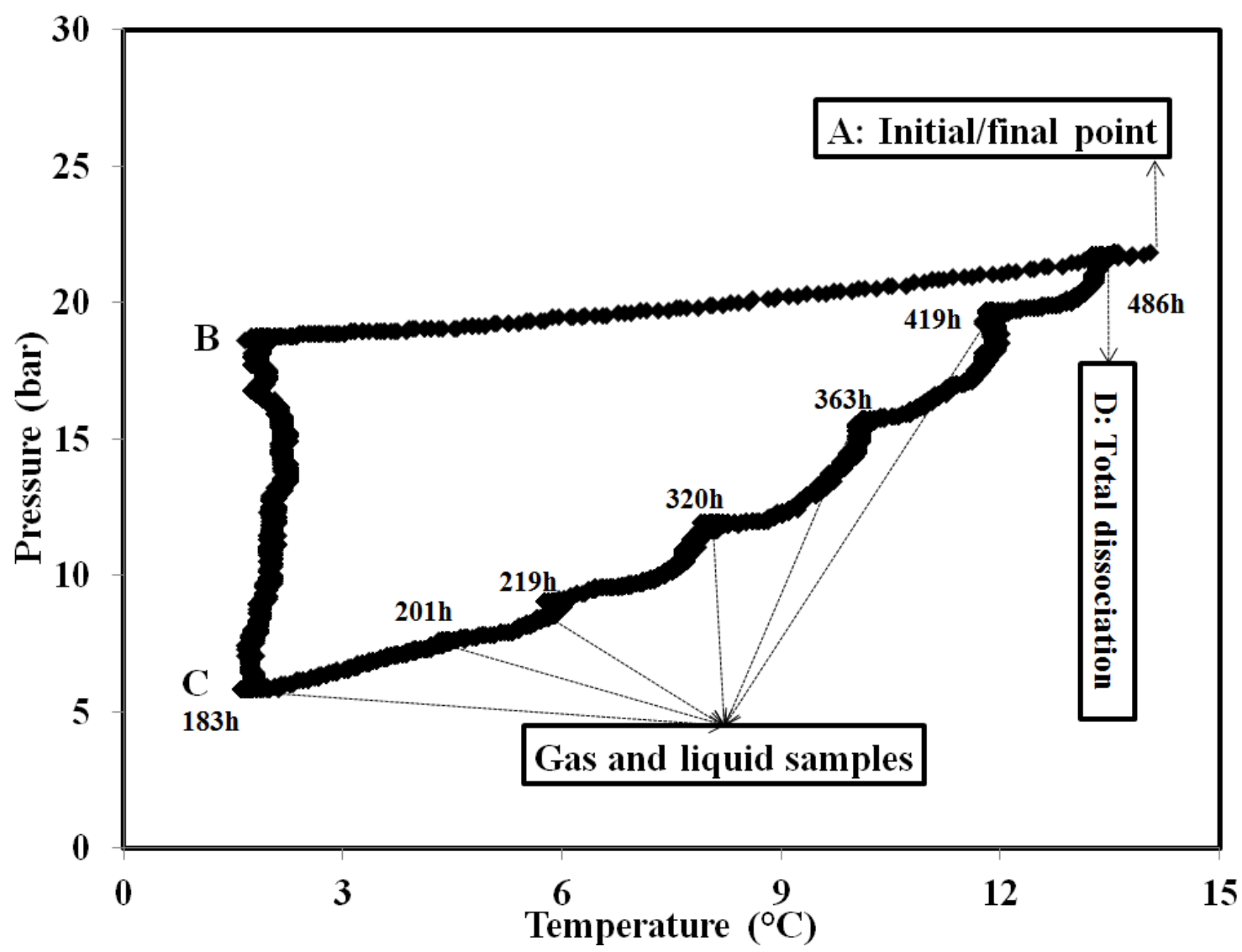

Figure 4. The pressure change versus temperature during the quick crystallization process in the case of ethane-butane mixture. The numbers in the figure correspond to the time of taking samples (from beginning of experiment)

Figure 5 shows temperature- pressure evolution during the slow crystallization procedure for ethane-butane mixture. As seen in this figure, the process was started with the same initial conditions as quick crystallization (A). But in this procedure, the temperature was decreased in a slow stepwise manner to negate the influence of kinetics as much as possible. This procedure is closer to the steady state processes. B was the first vapor-liquid-hydrate equilibrium point. The temperature was then decreased step by step until the end of crystallization (C). Several gas and liquid samples were taken for analysis. 


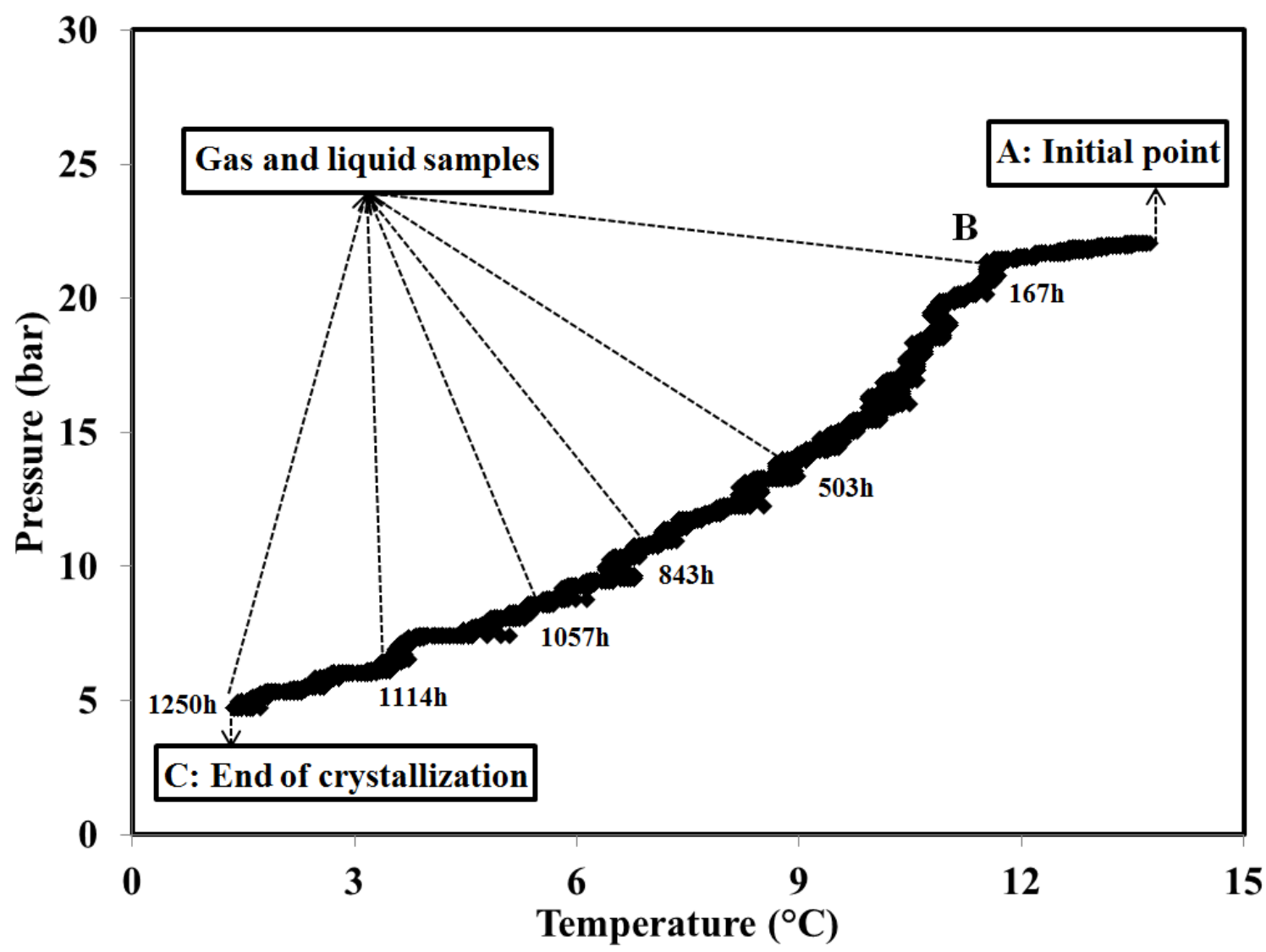

Figure 5. Temperature- pressure evolution during the slow crystallization procedure for ethane-butane mixture. The numbers in the figure correspond to the time of taking samples (from beginning of experiment)

These two procedures were performed for all the mentioned mixtures. The results are provided in the following sections.

\subsection{Experimental results}

Table 7 and Table 8 present experimental results including temperature, pressure and guest composition in gas, liquid and hydrate phases and gas solubility in liquid phase for all the mixtures according to the different rates of crystallization. These tables provide several remarkable results. Firstly, for a desired temperature, the equilibrium pressure at final state was different according to the rate of crystallization. For instance, for $\mathrm{CO}_{2}-\mathrm{C}_{3} \mathrm{H}_{8}$ mixture, at final state $\left(1.8^{\circ} \mathrm{C}\right)$, the equilibrium pressures for quick and slow processes were notably 16.4 and 14.3 bar, respectively. Figure 6 illustrates temperature-pressure diagram of all the mixtures for both crystallization procedures. However, in the case of mixtures involving butane, the final pressure was almost equal. For example for ternary mixture of $\mathrm{CH}_{4}-\mathrm{C}_{2} \mathrm{H}_{6}-\mathrm{C}_{4} \mathrm{H}_{10}$, the pressures at final state for quick and slow at $1.7^{\circ} \mathrm{C}$ were 17.8 and 18.2 bar. 
Table 7. Experimental results of guest composition in all phases regarding to the equilibrium temperature and pressure for two different rates of crystallization

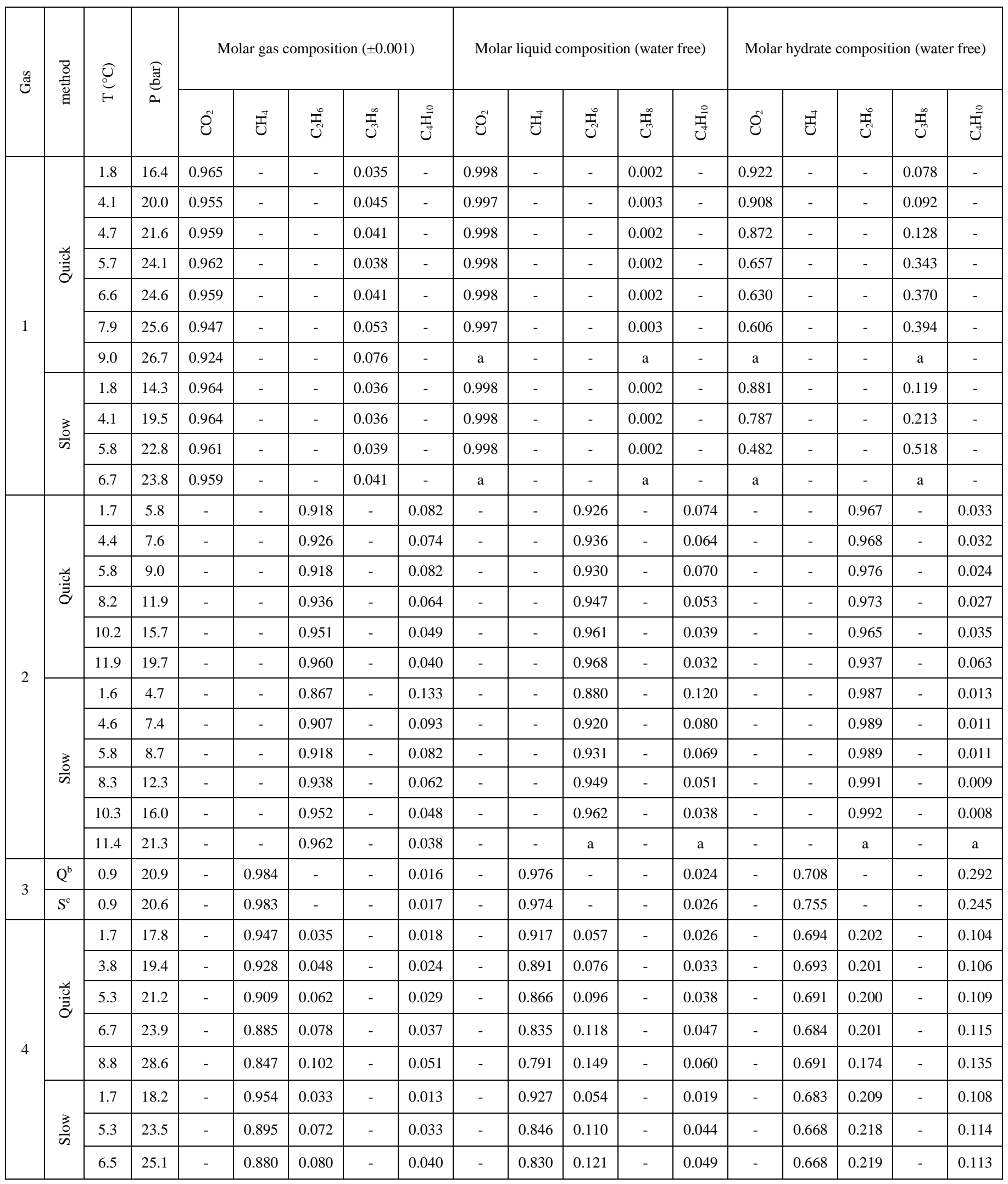




\begin{tabular}{|c|c|c|c|c|c|c|c|c|c|c|c|c|c|c|c|c|c|c|}
\hline \multirow{4}{*}{5} & \multirow{3}{*}{ 莺 } & 0.1 & 9.0 & 0.277 & - & 0.525 & 0.198 & - & 0.862 & - & 0.100 & 0.038 & - & 0.368 & - & 0.369 & 0.263 & - \\
\hline & & 4.3 & 11.1 & 0.281 & - & 0.511 & 0.208 & - & 0.869 & - & 0.094 & 0.037 & - & 0.367 & - & 0.355 & 0.278 & - \\
\hline & & 7.0 & 15.3 & 0.269 & - & 0.498 & 0.233 & - & 0.864 & - & 0.094 & 0.042 & - & 0.494 & - & 0.148 & 0.358 & - \\
\hline & $S^{b}$ & 0.0 & 6.5 & 0.332 & & 0.540 & 0.128 & - & 0.891 & - & 0.088 & 0.021 & - & 0.176 & - & 0.492 & 0.332 & - \\
\hline \multirow{4}{*}{6} & \multirow{4}{*}{ 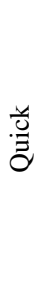 } & 4.3 & 11.0 & - & 0.861 & 0.094 & 0.031 & 0.014 & - & 0.795 & 0.143 & 0.044 & 0.018 & - & 0.626 & 0.143 & 0.209 & 0.022 \\
\hline & & 7.2 & 13.4 & - & 0.823 & 0.107 & 0.054 & 0.016 & - & 0.752 & 0.155 & 0.074 & 0.019 & - & 0.619 & 0.138 & 0.221 & 0.022 \\
\hline & & 10.6 & 18.0 & - & 0.771 & 0.118 & 0.093 & 0.018 & - & 0.699 & 0.165 & 0.117 & 0.019 & - & 0.607 & 0.124 & 0.248 & 0.021 \\
\hline & & 13.3 & 21.7 & - & 0.743 & 0.118 & 0.121 & 0.018 & - & 0.676 & 0.160 & 0.146 & 0.018 & - & 0.439 & 0.232 & 0.274 & 0.056 \\
\hline
\end{tabular}

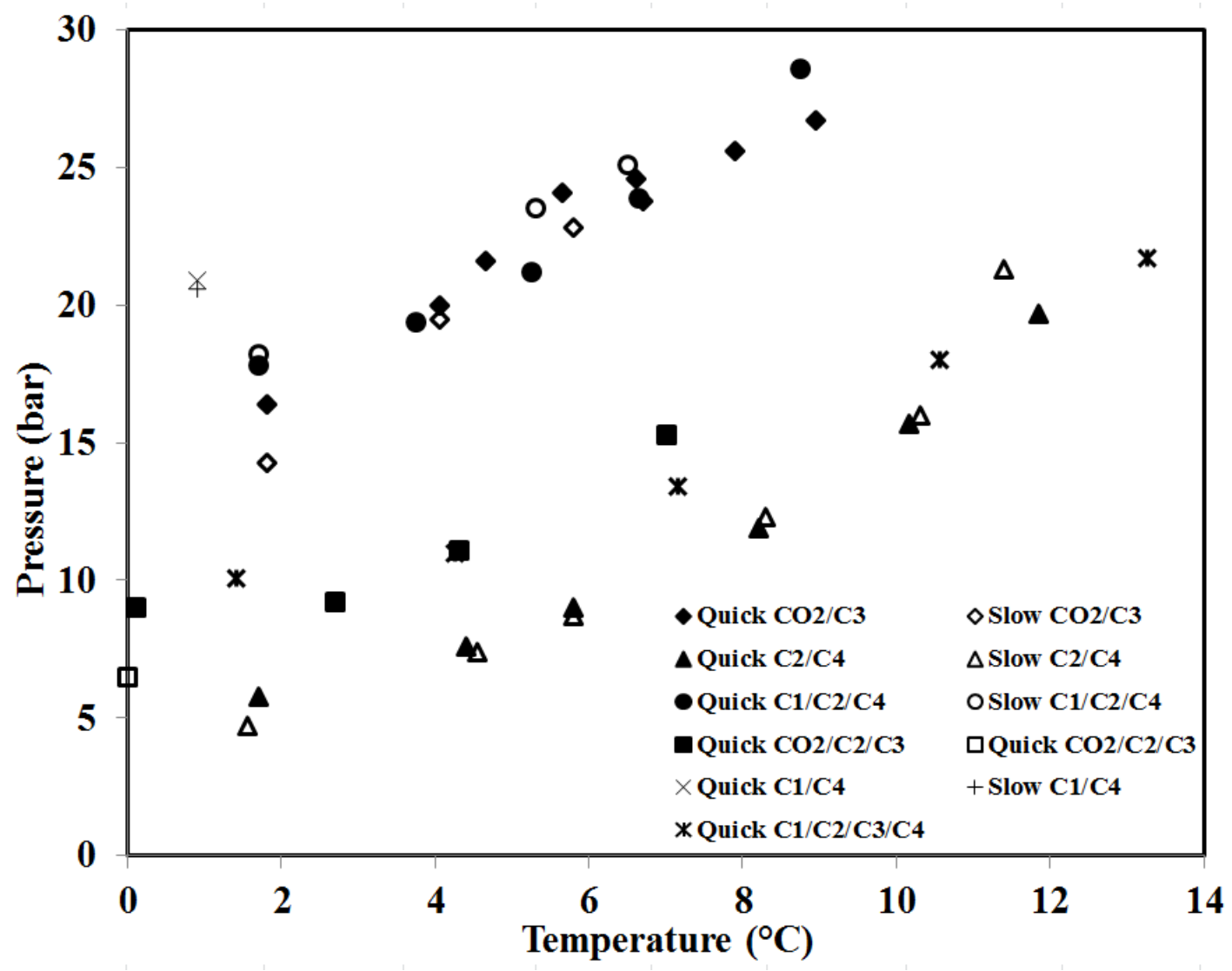

Figure 6. The pressure-temperature diagram of mixed gas hydrates involving two rates of crystallization. C1, $\mathrm{C} 2, \mathrm{C} 3$ and $\mathrm{C} 4$ stand for methane, ethane, propane and butane. 
Table 8. Gas solubility in liquid phase during the course of experiments

\begin{tabular}{|c|c|c|c|c|c|c|c|c|}
\hline \multirow{2}{*}{ క్ } & \multirow{2}{*}{ 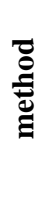 } & \multirow{2}{*}{$\underbrace{O}_{=}$} & \multirow{2}{*}{ 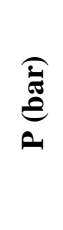 } & \multicolumn{5}{|c|}{ Gas solubility in liquid phase (mmol/L) } \\
\hline & & & & $\bigcup^{\sim}$ & $\ddot{U}$ & $\underbrace{0}$ & $\underbrace{\infty}$ & $\stackrel{\theta}{\exists}$ \\
\hline \multirow{11}{*}{1} & \multirow{7}{*}{ 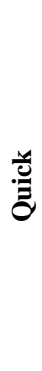 } & 1.8 & 16.4 & 935.2 & - & - & 2.0 & - \\
\hline & & 4.1 & 20.0 & 1123.1 & - & - & 3.0 & - \\
\hline & & 4.7 & 21.6 & 1206.8 & - & - & 2.9 & - \\
\hline & & 5.7 & 24.1 & 1351.4 & - & - & 3.0 & - \\
\hline & & 6.6 & 24.6 & 1341.6 & - & - & 3.2 & - \\
\hline & & 7.9 & 25.6 & 1329.5 & - & - & 4.1 & - \\
\hline & & 9.0 & 26.7 & 1309.3 & - & - & 5.8 & - \\
\hline & \multirow{4}{*}{$\frac{0}{\sigma}$} & 1.8 & 14.3 & 662.2 & - & - & 1.4 & - \\
\hline & & 4.1 & 19.5 & 977.7 & - & - & 2.1 & - \\
\hline & & 5.8 & 22.8 & 1180.6 & - & - & 2.7 & - \\
\hline & & 6.7 & 23.8 & 1343.8 & - & - & 3.4 & - \\
\hline \multirow{12}{*}{2} & \multirow{6}{*}{ 弟 } & 1.7 & 5.8 & - & - & 19.0 & - & 1.6 \\
\hline & & 4.4 & 7.6 & - & - & 23.0 & - & 1.6 \\
\hline & & 5.8 & 9.0 & - & - & 26.2 & - & 2.0 \\
\hline & & 8.2 & 11.9 & - & - & 34.2 & - & 1.9 \\
\hline & & 10.2 & 15.7 & - & - & 45.1 & - & 1.8 \\
\hline & & 11.9 & 19.7 & - & - & 59.8 & - & 1.9 \\
\hline & \multirow{6}{*}{$\frac{3}{\sigma a}$} & 1.6 & 4.7 & - & - & 10.7 & - & 1.5 \\
\hline & & 4.6 & 7.4 & - & - & 17.5 & - & 1.5 \\
\hline & & 5.8 & 8.7 & - & - & 20.4 & - & 1.5 \\
\hline & & 8.3 & 12.3 & - & - & 29.2 & - & 1.6 \\
\hline & & 10.3 & 16.0 & - & - & 36.8 & - & 1.5 \\
\hline & & 11.4 & 21.3 & - & - & 53.2 & - & 1.7 \\
\hline \multirow{2}{*}{3} & $\mathbf{Q}^{\mathbf{a}}$ & 0.9 & 20.9 & - & 43.3 & - & - & 1.1 \\
\hline & $\mathbf{S}^{\mathbf{b}}$ & 0.9 & 20.6 & - & 42.7 & - & - & 1.1 \\
\hline \multirow{8}{*}{4} & \multirow{5}{*}{ 晃 } & 1.7 & 17.8 & - & 35.5 & 2.2 & - & 1.0 \\
\hline & & 3.8 & 19.4 & - & 37.2 & 3.2 & - & 1.4 \\
\hline & & 5.3 & 21.2 & - & 37.7 & 4.2 & - & 1.7 \\
\hline & & 6.7 & 23.9 & - & 40.3 & 5.7 & - & 2.2 \\
\hline & & 8.8 & 28.6 & - & 45.8 & 8.6 & - & 3.5 \\
\hline & \multirow{3}{*}{$\frac{3}{\sigma}$} & 1.7 & 18.2 & - & 34.6 & 2.0 & - & 0.7 \\
\hline & & 5.3 & 23.5 & - & 40.5 & 5.3 & - & 2.1 \\
\hline & & 6.5 & 25.1 & - & 41.3 & 6.0 & - & 2.4 \\
\hline
\end{tabular}




\begin{tabular}{|c|c|c|c|c|c|c|c|c|}
\hline \multirow{5}{*}{5} & \multirow{4}{*}{ 光 } & 0.1 & 9.0 & 153.9 & - & 17.8 & 6.7 & - \\
\hline & & 2.7 & 9.2 & 150.4 & - & 16.8 & 6.1 & - \\
\hline & & 4.3 & 11.1 & 175.3 & - & 19.1 & 7.4 & - \\
\hline & & 7.0 & 15.3 & 229.5 & - & 25.0 & 11.0 & - \\
\hline & $\mathbf{S}^{\mathbf{b}}$ & 0.0 & 6.5 & 121.1 & & 12.0 & 2.8 & - \\
\hline \multirow{5}{*}{6} & \multirow{5}{*}{ 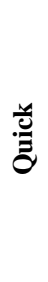 } & 1.4 & 10.1 & - & 18.8 & 3.3 & 0.6 & 0.4 \\
\hline & & 4.3 & 11.0 & - & 18.8 & 3.4 & 1.1 & 0.4 \\
\hline & & 7.2 & 13.4 & - & 21.2 & 4.4 & 2.1 & 0.5 \\
\hline & & 10.6 & 18.0 & - & 25.8 & 6.1 & 4.3 & 0.7 \\
\hline & & 13.3 & 21.7 & - & 29.8 & 7.0 & 6.5 & 0.8 \\
\hline \multicolumn{2}{|c|}{$\mathbf{u}^{\mathbf{c}}$} & $0.2^{\circ} \mathrm{C}$ & 0.1 bar & \multicolumn{5}{|c|}{$0.3 \mathrm{mmol} / \mathrm{L}$} \\
\hline \multicolumn{9}{|c|}{$\begin{array}{l}{ }^{\mathrm{a}} \text { Quick } \\
{ }^{\mathrm{b}} \text { Slow }\end{array}$} \\
\hline
\end{tabular}

Secondly, guest distribution in hydrate phase differed as the rate of crystallization changed. Additionally, the composition of heavier hydrocarbons in hydrate phase was significantly higher than in the gas phase. Finally, the composition of propane and butane in hydrate phase decreased from the first vapor-liquid-hydrate equilibrium point to the final state in both crystallization mechanisms. As an illustration, the butane composition in $\mathrm{C}_{2} \mathrm{H}_{6}-\mathrm{C}_{4} \mathrm{H}_{10}$ mixture at the first VLH equilibrium for quick process was 0.063 mole fraction, but at the final state, it changed to 0.033 mole fraction. This demonstrates that the enclathration of heavier molecules at the start of crystallization plays more important role than near the final state.

Table 9 shows the experimental results including hydrate volume and density, water conversion, hydration number and storage capacity for all the mixed gas hydrates comparing quick and slow crystallization rates. The table shows that for a mixed gas hydrate, water conversion at slow crystallization was generally lower than in the quick crystallization rate at final state. This means that less hydrate crystals formed and more occupation of cavities occurred. Storage cavity defines as the volume of the gas in hydrate phase at standard conditions per volume of hydrate. Experimental results showed that storage capacity and hydration number for mixed gas hydrates were also different according the rate of crystallization. In all cases, more storage capacity occurred at slow crystallization. For instance, the storage capacity of $\mathrm{CO}_{2}-\mathrm{C}_{2} \mathrm{H}_{6}-\mathrm{C}_{3} \mathrm{H}_{8}$ hydrates at final state $\left(0.1^{\circ} \mathrm{C}\right)$, for slow crystallization was $142.2 \mathrm{~V} / \mathrm{V}$ compare to $95.5 \mathrm{~V} / \mathrm{V}$ for quick crystallization. This may prove significant when storing natural gas for transportation use. In addition note that the hydration numbers at final state for slow and quick crystallization were 6.9 and 10.3 , respectively.

Although for hydrocarbon mixtures, the hydrate density was similar for both crystallization rates, for the mixtures that included carbon dioxide the difference was considerable (for example, hydrate density of $\mathrm{CO}_{2}-\mathrm{C}_{3} \mathrm{H}_{8}$ mixture at final state for quick and slow was 1.09 and $1.40 \mathrm{~g} / \mathrm{cm}^{3}$, 
respectively). At slow crystallization for this mixture, the hydrate volume was significantly lower than quick crystallization $\left(105 \mathrm{~cm}^{3}\right.$ at slow compared to $172 \mathrm{~cm}^{3}$ for quick at $\left.1.8^{\circ} \mathrm{C}\right)$. Moreover, the hydration number at slow crystallization was about two times less than quick crystallization. This means that more guest molecules were encased in hydrate phase. Hence, the hydrate densities at slow crystallization for $\mathrm{CO}_{2}-\mathrm{C}_{3} \mathrm{H}_{8}$ were much larger than quick crystallization.

One of the most important observations regarding to the hydrate properties in Table 9, is the hydrate volume findings. At slow crystallization procedure for all the mixtures, the hydrate volume and water conversion were noticeably lower than at quick crystallization. Figure 7 presents clearly the difference in hydrate volume according to the rate of crystallization.

Table 9. Hydrate phase properties during the course of experiments for two different crystallization rates

\begin{tabular}{|c|c|c|c|c|c|c|c|c|}
\hline Gas & Method & $\mathrm{T}\left({ }^{\circ} \mathrm{C}\right)$ & $\mathrm{P}($ bar $)$ & $\begin{array}{c}\text { Hydrate } \\
\text { volume } \\
\left(\mathrm{cm}^{3}\right)\end{array}$ & $\begin{array}{c}\text { Hydration } \\
\text { number }\end{array}$ & $\begin{array}{l}\text { Hydrate } \\
\text { density } \\
\left(\mathrm{g} / \mathrm{cm}^{3}\right)\end{array}$ & $\begin{array}{c}\text { Storage } \\
\text { capacity } \\
(\mathrm{V} / \mathrm{V})\end{array}$ & $\begin{array}{c}\text { Water } \\
\text { conversion } \\
(\%)\end{array}$ \\
\hline \multirow{11}{*}{1} & \multirow{7}{*}{ Quick } & 1.8 & 16.4 & 172.6 & 6.4 & 1.09 & 153.6 & 13.3 \\
\hline & & 4.1 & 20.0 & 100.5 & 6.0 & 1.11 & 163.6 & 7.8 \\
\hline & & 4.7 & 21.6 & 87.0 & 7.2 & 1.06 & 136.4 & 6.8 \\
\hline & & 5.7 & 24.1 & 48.1 & 11.3 & 0.96 & 86.6 & 3.8 \\
\hline & & 6.6 & 24.6 & 42.3 & 12.1 & 0.95 & 81.5 & 3.3 \\
\hline & & 7.9 & 25.6 & 37.8 & 21.4 & 0.88 & 46.0 & 3.0 \\
\hline & & 9.0 & 26.7 & $\mathrm{a}$ & $\mathrm{a}$ & $\mathrm{a}$ & $\mathrm{a}$ & $\mathrm{a}$ \\
\hline & \multirow{4}{*}{ Slow } & 1.8 & 14.3 & 105.0 & 3.1 & 1.40 & NA & 8.2 \\
\hline & & 4.1 & 19.5 & 42.9 & 2.5 & 1.56 & $\mathrm{NA}$ & 3.3 \\
\hline & & 5.8 & 22.8 & 22.4 & 3.5 & 1.34 & NA & 1.7 \\
\hline & & 6.7 & 23.8 & $\mathrm{a}$ & $\mathrm{a}$ & $\mathrm{a}$ & $\mathrm{a}$ & $\mathrm{a}$ \\
\hline \multirow{12}{*}{2} & \multirow{6}{*}{ Quick } & 1.7 & 5.8 & 259.6 & 7.8 & 0.96 & 125.6 & 25.6 \\
\hline & & 4.4 & 7.6 & 252.7 & 8.3 & 0.95 & 117.9 & 25.1 \\
\hline & & 5.8 & 9.0 & 234.2 & 8.4 & 0.95 & 117.2 & 23.4 \\
\hline & & 8.2 & 11.9 & 196.2 & 8.6 & 0.95 & 114.3 & 19.7 \\
\hline & & 10.2 & 15.7 & 150.8 & 9.7 & 0.93 & 100.8 & 15.2 \\
\hline & & 11.9 & $\begin{array}{l}19.7 \\
\end{array}$ & 56.4 & 8.7 & 0.95 & 112.8 & 5.7 \\
\hline & \multirow{6}{*}{ Slow } & 1.6 & 4.7 & 253.8 & 7.3 & 0.97 & 134.8 & 25.6 \\
\hline & & 4.6 & 7.4 & 184.6 & 6.1 & 1.00 & 161.9 & 18.6 \\
\hline & & 5.8 & 8.7 & 173.4 & 6.1 & 1.00 & 160.2 & 17.4 \\
\hline & & 8.3 & 12.3 & 119.8 & 5.5 & 1.03 & 179.9 & 11.9 \\
\hline & & 10.3 & 16.0 & 107.6 & 7.2 & 0.97 & 136.4 & 10.7 \\
\hline & & 11.4 & 21.3 & $\mathrm{a}$ & $\mathrm{a}$ & $\mathrm{a}$ & $\mathrm{a}$ & $\mathrm{a}$ \\
\hline \multirow{2}{*}{3} & Quick & 0.9 & 20.9 & 38.3 & 11.6 & 0.9 & 88.0 & 3.8 \\
\hline & Slow & 0.9 & 20.6 & 37.3 & 9.3 & 0.91 & 104.7 & 3.67 \\
\hline \multirow{8}{*}{4} & \multirow{5}{*}{ Quick } & 1.7 & 17.8 & 108.0 & 6.1 & 0.96 & 162.1 & 8.5 \\
\hline & & 3.8 & 19.4 & 57.0 & 3.6 & 1.07 & 271.2 & 4.5 \\
\hline & & 5.3 & 21.2 & 81.2 & 6.1 & 0.96 & 161.8 & 6.5 \\
\hline & & 6.7 & 23.9 & 70.2 & 7.4 & 0.93 & 132.0 & 5.6 \\
\hline & & 8.8 & 28.6 & 20.7 & 10.0 & 0.90 & 98.6 & 1.7 \\
\hline & \multirow{3}{*}{ Slow } & 1.7 & 18.2 & 85.6 & 4.9 & 1.00 & $\begin{array}{l}199.1 \\
\end{array}$ & 6.8 \\
\hline & & 5.3 & 23.5 & 32.0 & 3.3 & 1.11 & NA & 2.5 \\
\hline & & 6.5 & 25.1 & 40.4 & 5.3 & 0.99 & 186.6 & 3.2 \\
\hline \multirow{2}{*}{5} & \multirow{2}{*}{ Quick } & 0.1 & 9.0 & 159.5 & 10.3 & 0.96 & 95.5 & 12.6 \\
\hline & & 2.7 & 9.2 & 142.8 & 9.3 & 0.97 & 105.8 & 11.3 \\
\hline
\end{tabular}




\begin{tabular}{|c|c|c|c|c|c|c|c|c|}
\hline & & 4.3 & 11.1 & 123.3 & 10.6 & 0.95 & 92.9 & 9.8 \\
\cline { 3 - 9 } & 7.0 & 15.3 & 42.4 & 16.2 & 0.90 & 60.8 & 3.4 \\
\cline { 2 - 9 } & Slow & 0.0 & 6.5 & 141.0 & 6.9 & 1.02 & 142.2 & 11.1 \\
\hline \multirow{3}{*}{6} & & 1.4 & 10.1 & 169.2 & 8.1 & 0.92 & 120.9 & 16.7 \\
\cline { 3 - 9 } & 4.3 & 11.0 & 166.6 & 8.6 & 0.92 & 114.7 & 16.5 \\
\cline { 3 - 9 } & 7.2 & 13.4 & 136.4 & 8.8 & 0.91 & 111.3 & 13.6 \\
\hline & 10.6 & 18.0 & 94.5 & 12.7 & 0.88 & 77.1 & 9.5 \\
\cline { 3 - 9 } & 13.3 & 21.7 & 42.2 & 74.3 & 0.81 & 13.2 & 4.2 \\
\hline \multicolumn{2}{|c|}{$\begin{array}{c}\text { Standard } \\
\text { uncertainty }\end{array}$} & $0.2^{\circ} \mathrm{C}$ & $0.1 \mathrm{bar}$ & $0.4 \mathrm{~cm}^{3}$ & 0.5 & $0.05 \mathrm{~g} / \mathrm{cm}^{3}$ & $0.5 \mathrm{~V} / \mathrm{V}$ & 0.4 \\
\hline
\end{tabular}

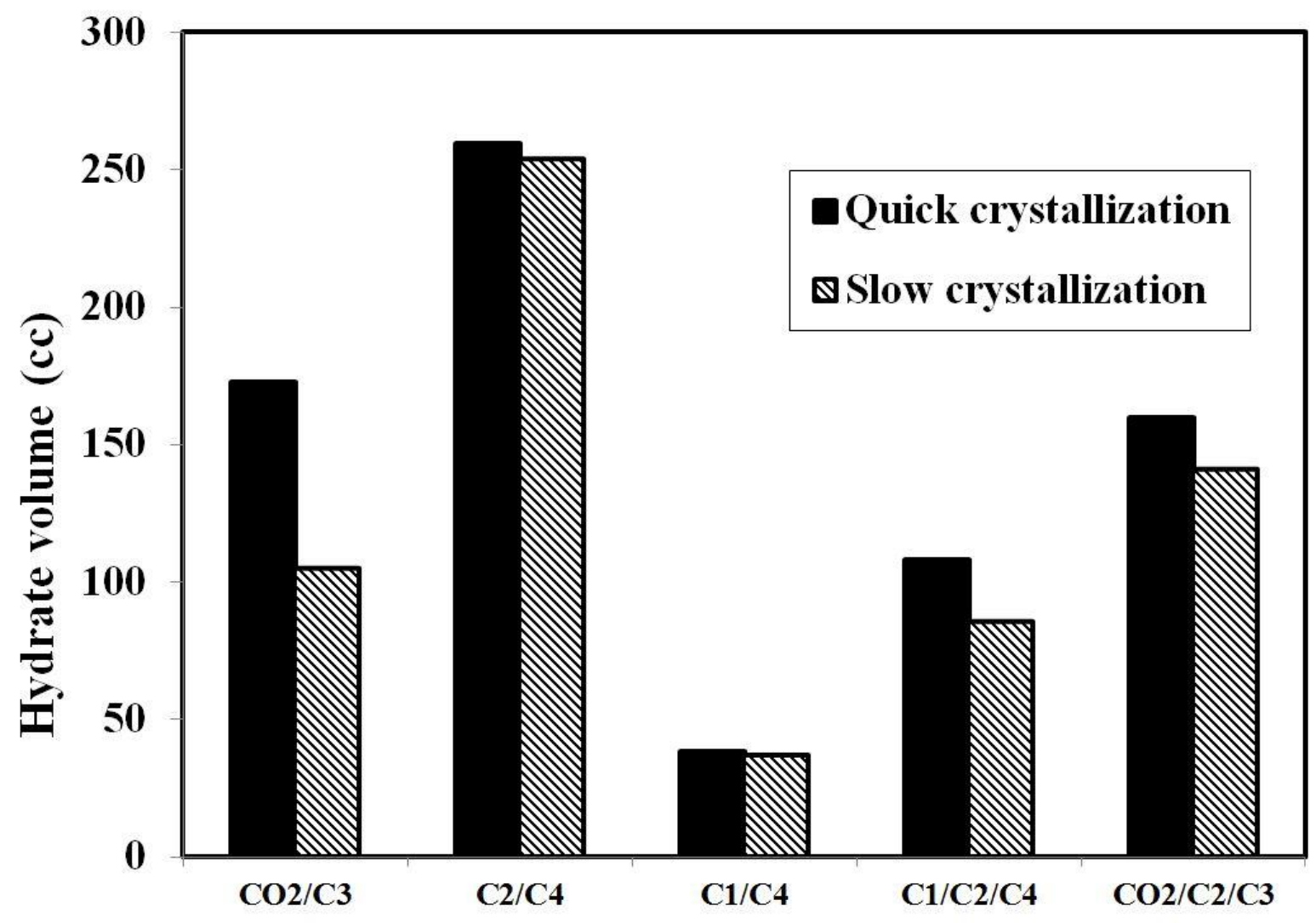

Figure 7. Hydrate volume for different mixtures for quick and slow crystallization procedures

These outcomes explain the effect of kinetics on hydrate formation, crystallization and properties. This is to say that the enclathration and distribution of guest molecules in hydrate phase as well as their selectivity intensely depend on the driving force of crystallization. Moreover, the difference in final pressure highlights the nagging question about the thermodynamic equilibrium. Is it certain that the thermodynamic equilibrium has been reached? The results of thermodynamic model in the following section clarify some crucial indications on how to better understand the kinetic effects on equilibrium state of mixed hydrates.

\subsection{Modeling results}


Results of thermodynamic model to predict equilibrium pressure (temperature) as well as guest composition in hydrate phase are presented here. Table 10 shows modeling results including hydrate pressure and composition, not only for the final state of equilibrium, but also during the crystallization process. It should be noted that simulation results for both structures I and II are presented in the following table.

Table 10. Results of thermodynamic model for hydrate pressure and composition

\begin{tabular}{|c|c|c|c|c|c|c|c|c|c|c|c|c|c|c|c|}
\hline \multirow{3}{*}{ ש } & \multirow{3}{*}{ 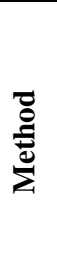 } & \multirow{3}{*}{ 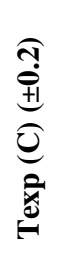 } & \multirow{3}{*}{ 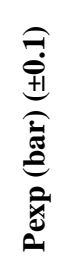 } & \multicolumn{6}{|c|}{ Structure I (simulated results) } & \multicolumn{6}{|c|}{ Structure II (simulated results) } \\
\hline & & & & \multirow{2}{*}{ 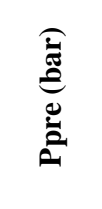 } & \multicolumn{5}{|c|}{ Hydrate composition (water free) } & \multirow{2}{*}{ 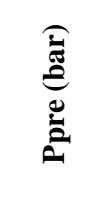 } & \multicolumn{5}{|c|}{ Hydrate composition (water free) } \\
\hline & & & & & $\mathrm{CO}_{2}$ & $\mathrm{CH}_{4}$ & $\mathrm{C}_{2} \mathrm{H}_{6}$ & $\mathrm{C}_{3} \mathrm{H}_{8}$ & $\mathrm{C}_{4} \mathrm{H}_{10}$ & & $\mathrm{CO}_{2}$ & $\mathrm{CH}_{4}$ & $\mathrm{C}_{2} \mathrm{H}_{6}$ & $\mathrm{C}_{3} \mathrm{H}_{8}$ & $\mathrm{C}_{4} \mathrm{H}_{10}$ \\
\hline \multirow{13}{*}{1} & \multirow{7}{*}{ 苍 } & 1.8 & 16.4 & 12.7 & 0.819 & - & - & 0.181 & - & 8.2 & 0.673 & - & - & 0.327 & - \\
\hline & & 4.1 & 20.0 & 15.6 & 0.789 & - & - & 0.211 & - & 9.8 & 0.668 & - & - & 0.332 & - \\
\hline & & 4.7 & 21.6 & 17.1 & 0.807 & - & - & 0.193 & - & 10.8 & 0.674 & - & - & 0.326 & - \\
\hline & & 5.7 & 24.1 & 19.6 & 0.823 & - & - & 0.177 & - & 12.6 & 0.680 & - & - & 0.320 & - \\
\hline & & 6.6 & 24.6 & 21.7 & 0.817 & - & - & 0.183 & - & 13.7 & 0.679 & - & - & 0.321 & - \\
\hline & & 7.9 & 25.6 & 24.0 & 0.783 & - & - & 0.217 & - & 14.6 & 0.671 & - & - & 0.329 & - \\
\hline & & 9.0 & 26.7 & 24.9 & NA & - & - & NA & - & 14.6 & NA & - & - & NA & - \\
\hline & \multicolumn{2}{|c|}{ dev. } & \multicolumn{2}{|c|}{$\mathbf{1 5 . 5 \%}$} & 0.136 & - & - & 0.136 & - & $47.3 \%$ & 0.137 & - & - & 0.137 & - \\
\hline & \multirow{4}{*}{$\frac{3}{0}$} & 1.8 & 14.3 & 12.60 & 0.812 & - & - & 0.188 & - & 8.1 & 0.671 & - & - & 0.329 & - \\
\hline & & 4.1 & 19.5 & 16.30 & 0.822 & - & - & 0.178 & - & 10.5 & 0.677 & - & - & 0.323 & - \\
\hline & & 5.8 & 22.8 & 19.90 & 0.821 & - & - & 0.179 & - & 12.7 & 0.680 & - & - & 0.320 & - \\
\hline & & 6.7 & 23.8 & 21.90 & NA & - & - & NA & - & 13.9 & NA & - & - & NA & - \\
\hline & \multicolumn{2}{|c|}{ dev. } & \multicolumn{2}{|c|}{$12.3 \%$} & 0.084 & - & - & 0.084 & - & $43.8 \%$ & 0.187 & - & - & 0.187 & - \\
\hline & & & & & & & & & & & & & & & \\
\hline \multirow{14}{*}{2} & \multirow{6}{*}{ 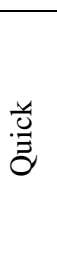 } & 1.7 & 5.8 & 3.6 & - & - & 0.572 & - & 0.428 & 28.3 & - & - & $\mathrm{a}$ & - & $\mathrm{a}$ \\
\hline & & 4.4 & 7.6 & 5.3 & - & - & 0.615 & - & 0.385 & 28.1 & - & - & $\mathrm{a}$ & - & $\mathrm{a}$ \\
\hline & & 5.8 & 9.0 & 6.1 & - & - & 0.596 & - & 0.404 & 28.4 & - & - & $\mathrm{a}$ & - & $\mathrm{a}$ \\
\hline & & 8.2 & 11.9 & 9.1 & - & - & 0.678 & - & 0.322 & 33.8 & - & - & $\mathrm{a}$ & - & $\mathrm{a}$ \\
\hline & & 10.2 & 15.7 & 12.9 & - & - & 0.754 & - & 0.246 & 34.3 & - & - & $\mathrm{a}$ & - & $\mathrm{a}$ \\
\hline & & 11.9 & 19.7 & 17.3 & - & - & 0.807 & - & 0.193 & 34.6 & - & - & $\mathrm{a}$ & - & $\mathrm{a}$ \\
\hline & \multicolumn{2}{|c|}{ dev. } & \multicolumn{2}{|c|}{$28.2 \%$} & - & - & 0.294 & - & 0.294 & $208 \%$ & - & - & $\mathrm{a}$ & - & $\mathrm{a}$ \\
\hline & & 1.6 & 4.7 & 2.8 & - & - & 0.435 & - & 0.565 & 28.4 & - & - & $\mathrm{a}$ & - & $\mathrm{a}$ \\
\hline & & 4.6 & 7.4 & 4.9 & - & - & 0.555 & - & 0.445 & 28.2 & - & - & $\mathrm{a}$ & - & $\mathrm{a}$ \\
\hline & 3 & 5.8 & 8.7 & 6.1 & - & - & 0.598 & - & 0.402 & 28.4 & - & - & $\mathrm{a}$ & - & $\mathrm{a}$ \\
\hline & $\frac{0}{n}$ & 8.3 & 12.3 & 9.3 & - & - & 0.687 & - & 0.313 & 34.0 & - & - & $\mathrm{a}$ & - & $\mathrm{a}$ \\
\hline & & 10.3 & 16.0 & 13.2 & - & - & 0.758 & - & 0.242 & 34.2 & - & - & $\mathrm{a}$ & - & $\mathrm{a}$ \\
\hline & & 11.4 & 21.3 & 16.3 & - & - & NA & - & NA & 34.5 & - & - & $\mathrm{a}$ & - & $\mathrm{a}$ \\
\hline & & & & & - & - & 0.316 & - & 0.316 & $227 \%$ & - & - & $\mathrm{a}$ & - & $\mathrm{a}$ \\
\hline & & & & & & & & & & & & & & & \\
\hline & $\mathrm{Q}^{\mathrm{b}}$ & 0.9 & 20.9 & 13.0 & - & 0.521 & - & - & 0.479 & 16.8 & - & 0.806 & - & - & 0.194 \\
\hline 2 & & & & & - & 0.187 & - & - & 0.187 & $19.6 \%$ & - & 0.098 & - & - & 0.098 \\
\hline 3 & $\mathrm{~S}^{\mathrm{b}}$ & 0.9 & 20.6 & 12.5 & - & 0.507 & - & - & 0.493 & 16.8 & - & 0.800 & - & - & 0.200 \\
\hline & & & & & - & 0.248 & - & - & 0.248 & $18.4 \%$ & - & 0.045 & - & - & 0.045 \\
\hline & & & & & & & & & & & & & & & \\
\hline & & 1.7 & 17.8 & 12.0 & - & 0.237 & 0.098 & - & 0.335 & 17.2 & - & 0.765 & 0.069 & - & 0.166 \\
\hline 4 & 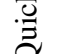 & 3.8 & 19.4 & 12.8 & - & 0.275 & 0.085 & - & 0.360 & 20.2 & - & 0.748 & 0.078 & - & 0.175 \\
\hline & & 5.3 & 21.2 & 13.3 & - & 0.300 & 0.069 & - & 0.368 & 22.8 & - & 0.736 & 0.087 & - & 0.176 \\
\hline
\end{tabular}




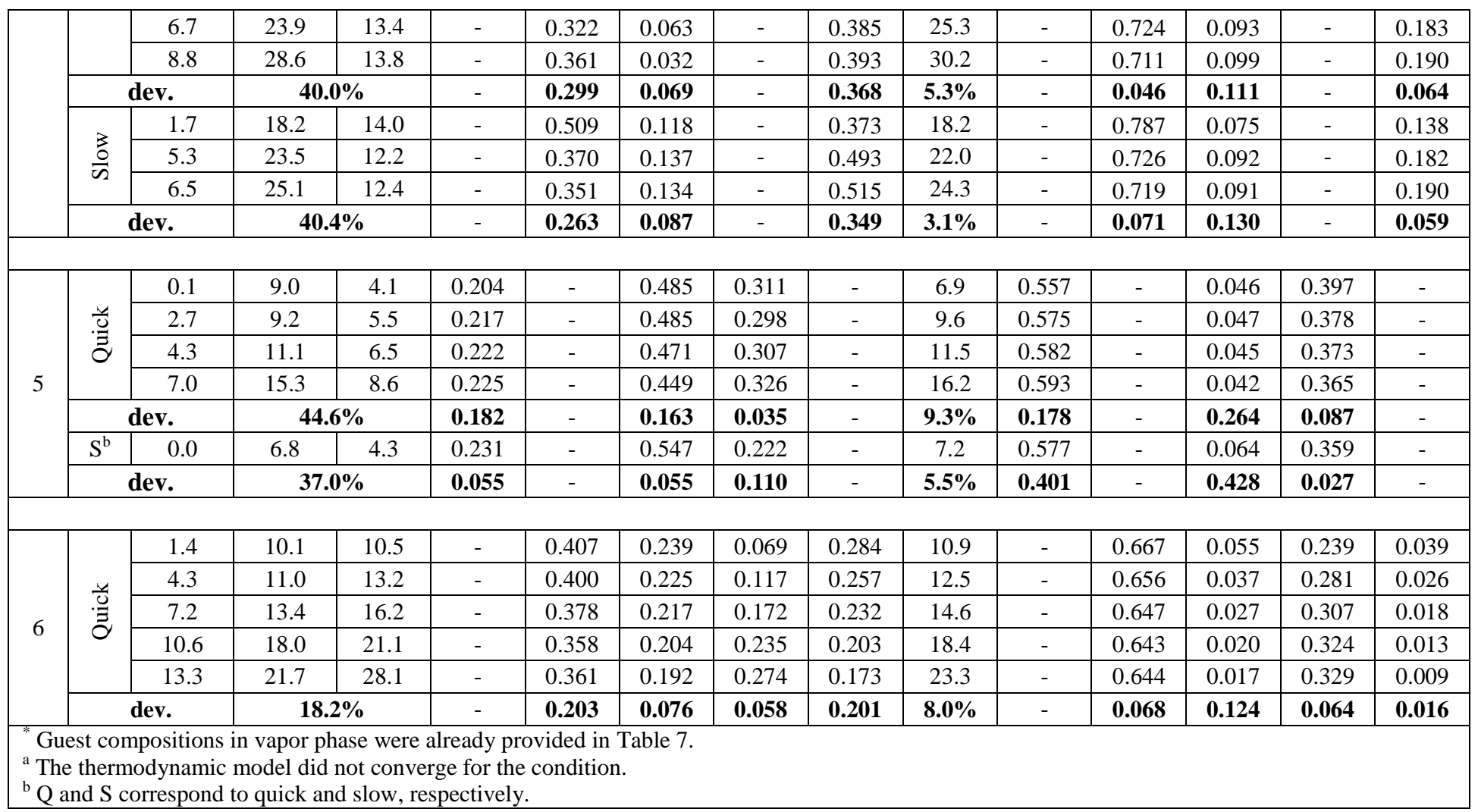

As seen in Table 10 for binary mixtures, in the case of $\mathrm{CO}_{2}-\mathrm{C}_{3} \mathrm{H}_{8}$, the results of thermodynamic model had a better accordance with the experimental data from slow crystallization for equilibrium pressure (12.3\% for slow compare to $15.5 \%$ for quick). This is more obvious for hydrate composition. The average absolute deviation for hydrate composition for slow process is about 0.08 , whilst near 0.14 for quick crystallization. However for binary mixtures including $\mathrm{C}_{4} \mathrm{H}_{10}$, the thermodynamic model almost failed to predict hydrate pressure and composition. It could be due to the Kihara parameters of butane. Ideally, a wide range of pure equilibrium data for each guest molecule is required to optimize Kihara parameters. Butane does not form hydrates by itself. Nevertheless in the presence of other hydrate formers, it can enter into the cavities. As a result, the Kihara parameters for butane are quite complicated to obtain. Secondly, for binary mixtures involving butane, the kinetic effects might have a significant influence on hydrate formation (regardless to the rate of crystallization); hence the results of experiments and thermodynamic model diverge considerably.

For ternary mixtures, the modeling results show that both mixtures formed structure II. Furthermore, thermodynamic model agreed well with the experimental results of slow crystallization (average deviation of $3.1 \%$ and $5.5 \%$ for $\mathrm{CO}_{2}-\mathrm{C}_{2} \mathrm{H}_{6}-\mathrm{C}_{3} \mathrm{H}_{8}$ and $\mathrm{CH}_{4}-\mathrm{C}_{2} \mathrm{H}_{6}-\mathrm{nC}_{4} \mathrm{H}_{10}$, respectively). However, the guest composition in hydrate phase for both crystallization rates was not well simulated, indicating the kinetic effects are considerable. 
The thermodynamic model predicts relatively well the hydrate formation pressure (average deviation: $8 \%$ ) and guest composition in hydrate phase (except ethane) for mixed $\mathrm{CH}_{4}-\mathrm{C}_{2} \mathrm{H}_{6}$ $\mathrm{C}_{3} \mathrm{H}_{8}-\mathrm{nC}_{4} \mathrm{H}_{10}$ hydrates.

These clarifications reveal some surprising consequences. The experimental results of slow crystallization process seemed to be closer to thermodynamic equilibrium (unlike the thermodynamic model). This suggests that the hydrate formation would be at thermodynamic equilibrium, if the kinetic effects could be circumvented as much as possible. Furthermore, the hydrate crystals at slow crystallization might be more homogeneous than quick crystallization process. Finally, the impact of kinetic considerations in both crystallization processes could not be ignored. Therefore, the hydrate formation of gas mixtures is clearly occurs at non-equilibrium conditions.

\section{Conclusion}

Gas hydrates from $\mathrm{CO}_{2}-\mathrm{CH}_{4}-\mathrm{C}_{2} \mathrm{H}_{6}-\mathrm{C}_{3} \mathrm{H}_{8}-\mathrm{nC}_{4} \mathrm{H}_{10}$ gas mixtures were studied. The aim was to measure hydrate phase properties such as hydrate composition, density and volume, storage capacity and water conversion. These were measured at equilibrium state (final state) as well as during the crystallization at non-equilibrium conditions. In addition, two different rates of crystallization applied to investigate the influence of kinetics on hydrate crystallization. Finally, the experimental results were compared to the thermodynamic model of van der Waals and Platteeuw using Kihara parameters to evaluate the kinetic effects on thermodynamic equilibrium.

One of the most noteworthy observations in our experimental data was that the hydrate volume at slow crystallization (case closer to steady-state process) was noticeably less than at quick crystallization. This concept should help to regulate more realistically the amount of kinetic inhibitors (KHI) or anti-agglomerants (AA) to use in flow-assurance issues potentially saving countless dollars in the current energy industry. Furthermore, the storage capacity at slow crystallization was greater than quick crystallization. This information could be essential for increased storage of gas hydrates especially pertinent in transportation use etc. Moreover, based on the data obtained, we suggest that the pressure and guest distribution in hydrate phase at final state is significantly influenced by the crystallization speed as opposed to what was previously understood.

In addition, the results of the thermodynamic model showed that for both crystallization methods, the kinetic effects had a non-negligible impact on the thermodynamic equilibrium of mixed gas hydrates. However, the results of thermodynamic model agreed better with the experimental data from slow crystallization for hydrate pressure and composition. This means that hydrate formation at slow crystallization is closer to thermodynamic equilibrium.

Finally, the authors suggest that in all applications of mixed clathrate hydrates where the thermodynamic equilibrium is taken into account, the kinetic effects could be a vital key to redesign the approach to have more accurate and realistic data. 


\section{Acknowledgements}

The authors wish to thank our colleagues for their technical supports; Fabien Chauvy, Richard Drogo and Hubert Faure and Chris Yukna for his help in proofreading.

\section{References}

[1] E.D. Sloan, C.A. Koh, Clathrate Hydrates of Natural Gases, 3rd ed., CRC Press, 2007.

[2] S. Mokhatab, R.J. Wilkens, K.J. Leontaritis, A Review of Strategies for Solving GasHydrate Problems in Subsea Pipelines, Energy Sources Part Recovery Util. Environ. Eff. 29 (2007) 39-45. doi:10.1080/009083190933988.

[3] J.L. Creek, Efficient Hydrate Plug Prevention, Energy Fuels. 26 (2012) 4112-4116. doi:10.1021/ef300280e.

[4] E.D. Sloan, A changing hydrate paradigm - from apprehension to avoidance to risk management, Fluid Phase Equilibria. 228 (2005) 67-74. doi:10.1016/j.fluid.2004.08.009.

[5] M. Di Lorenzo, Z.M. Aman, K. Kozielski, B.W.E. Norris, M.L. Johns, E.F. May, Modelling hydrate deposition and sloughing in gas-dominant pipelines, J. Chem. Thermodyn. 117 (2018) 81-90. doi:10.1016/j.jct.2017.08.038.

[6] T. Collett, J.-J. Bahk, R. Baker, R. Boswell, D. Divins, M. Frye, D. Goldberg, J. Husebø, C. Koh, M. Malone, M. Morell, G. Myers, C. Shipp, M. Torres, Methane Hydrates in NatureCurrent Knowledge and Challenges, J. Chem. Eng. Data. 60 (2015) 319-329. doi:10.1021/je500604h.

[7] R. Boswell, T.S. Collett, Current perspectives on gas hydrate resources, Energy Environ. Sci. 4 (2011) 1206-1215. doi:10.1039/C0EE00203H.

[8] A. Okwananke, J. Yang, B. Tohidi, E. Chuvilin, V. Istomin, B. Bukhanov, A. Cheremisin, Enhanced depressurisation for methane recovery from gas hydrate reservoirs by injection of compressed air and nitrogen, J. Chem. Thermodyn. 117 (2018) 138-146. doi:10.1016/j.jct.2017.09.028.

[9] D. Lim, H. Ro, Y. Seo, Y. Seo, J.Y. Lee, S.-J. Kim, J. Lee, H. Lee, Thermodynamic stability and guest distribution of $\mathrm{CH} 4 / \mathrm{N} 2 / \mathrm{CO} 2$ mixed hydrates for methane hydrate production using N2/CO2 injection, J. Chem. Thermodyn. 106 (2017) 16-21. doi:10.1016/j.jct.2016.11.012.

[10] S. Maghsoodloo Babakhani, A. Alamdari, Effect of maize starch on methane hydrate formation/dissociation rates and stability, J. Nat. Gas Sci. Eng. 26 (2015) 1-5. doi:10.1016/j.jngse.2015.05.026.

[11] C.A. Koh, E.D. Sloan, A.K. Sum, D.T. Wu, Fundamentals and applications of gas hydrates, Annu. Rev. Chem. Biomol. Eng. 2 (2011) 237-257. doi:10.1146/annurev-chembioeng061010-114152.

[12] J.J. Rajnauth, M. Barrufet, G. Falcone, Potential Industry Applications Using Gas Hydrate Technology, in: Society of Petroleum Engineers, 2010. doi:10.2118/133466-MS.

[13] V. Lachet, E. Béhar, Industrial Perspective on Natural Gas Hydrates, Oil Gas Sci. Technol. 55 (2000) 611-616. doi:10.2516/ogst:2000046.

[14] M. Massah, D. Sun, H. Sharifi, P. Englezos, Demonstration of gas-hydrate assisted carbon dioxide storage through horizontal injection in lab-scale reservoir, J. Chem. Thermodyn. 117 (2018) 106-112. doi:10.1016/j.jct.2017.09.019. 
[15] A. Eslamimanesh, A.H. Mohammadi, D. Richon, P. Naidoo, D. Ramjugernath, Application of gas hydrate formation in separation processes: A review of experimental studies, J. Chem. Thermodyn. 46 (2012) 62-71. doi:10.1016/j.jct.2011.10.006.

[16] M.N. Khan, P. Warrier, C.J. Peters, C.A. Koh, Review of vapor-liquid equilibria of gas hydrate formers and phase equilibria of hydrates, J. Nat. Gas Sci. Eng. 35, Part B (2016) 1388-1404. doi:10.1016/j.jngse.2016.06.043.

[17] H.-J. Ng, Hydrate Phase Composition for Multicomponent Gas Mixtures, Ann. N. Y. Acad. Sci. 912 (2000) 1034-1039. doi:10.1111/j.1749-6632.2000.tb06858.x.

[18] T. Kawasaki, K. Kikuchi, D. Terasaki, T. Okui, K. Myata, H. Hirayama, M. Ihara, Composition of Guests in Hydrates from Gas Mixture, in: Yokohama, Japan, 2002: pp. 424427.

[19] A.K. Sum, R.C. Burruss, E.D. Sloan, Measurement of Clathrate Hydrates via Raman Spectroscopy, J. Phys. Chem. B. 101 (1997) 7371-7377. doi:10.1021/jp970768e.

[20] S. Subramanian, A.. Ballard, R.. Kini, S.. Dec, E.. Sloan, Structural transitions in methane+ethane gas hydrates - Part I: upper transition point and applications, Chem. Eng. Sci. 55 (2000) 5763-5771. doi:10.1016/S0009-2509(00)00162-7.

[21] S. Subramanian, R.A. Kini, S.F. Dec, E.D. Sloan, Evidence of structure II hydrate formation from methane+ethane mixtures, Chem. Eng. Sci. 55 (2000) 1981-1999. doi:10.1016/S00092509(99)00389-9.

[22] B. Kvamme, T. Kuznetsova, B. Jensen, S. Stensholt, J. Bauman, S. Sjøblom, K. Nes Lervik, Consequences of $\mathrm{CO} 2$ solubility for hydrate formation from carbon dioxide containing water and other impurities, Phys Chem Chem Phys. 16 (2014) 8623-8638. doi:10.1039/C3CP53858C.

[23] T. Uchida, S. Takeya, Y. Kamata, I.Y. Ikeda, J. Nagao, T. Ebinuma, H. Narita, O. Zatsepina, B.A. Buffett, Spectroscopic Observations and Thermodynamic Calculations on Clathrate Hydrates of Mixed Gas Containing Methane and Ethane: Determination of Structure, Composition and Cage Occupancy, J. Phys. Chem. B. 106 (2002) 12426-12431. doi: $10.1021 / \mathrm{jp} 025884 \mathrm{i}$.

[24] J.M. Schicks, J.A. Ripmeester, The Coexistence of Two Different Methane Hydrate Phases under Moderate Pressure and Temperature Conditions: Kinetic versus Thermodynamic Products, Angew. Chem. 116 (2004) 3372-3375. doi:10.1002/ange.200453898.

[25] J.-M. Herri, F. Gruy, J.-S. Pic, M. Cournil, B. Cingotti, A. Sinquin, Interest of in situ turbidimetry for the characterization of methane hydrate crystallization: application to the study of kinetic inhibitors, Chem. Eng. Sci. 54 (1999a) 1849-1858.

[26] J.L. Peytavy, J.P. Monfort, C. Gaillard, Investigation of Methane Hydrate Formation in a Recirculating Flow Loop: Modeling of the Kinetics and Tests of Efficiency of Chemical Additives on Hydrate Inhibition, Oil Gas Sci. Technol. 54 (n.d.) 365-374. doi:10.2516/ogst:1999033.

[27] P.J. Murphy, S. Roberts, Melting and nucleation behaviour of clathrates in multivolatile fluid inclusions: evidence of thermodynamic disequilibrium, Chem. Geol. 135 (1997) 1-20. doi:10.1016/S0009-2541(96)00101-5.

[28] A.N. Salamatin, A. Falenty, W.F. Kuhs, Diffusion Model for Gas Replacement in an Isostructural CH4-CO2 Hydrate System, J. Phys. Chem. C. 121 (2017) 17603-17616. doi:10.1021/acs.jpcc.7b04391.

[29] J. Vatamanu, P.G. Kusalik, Molecular Insights into the Heterogeneous Crystal Growth of sI Methane Hydrate, J. Phys. Chem. B. 110 (2006) 15896-15904. doi:10.1021/jp061684l. 
[30] M.R. Walsh, C.A. Koh, E.D. Sloan, A.K. Sum, D.T. Wu, Microsecond Simulations of Spontaneous Methane Hydrate Nucleation and Growth, Science. 326 (2009) 1095-1098. doi:10.1126/science.1174010.

[31] L.C. Jacobson, W. Hujo, V. Molinero, Amorphous Precursors in the Nucleation of Clathrate Hydrates, J. Am. Chem. Soc. 132 (2010) 11806-11811. doi:10.1021/ja1051445.

[32] W. Shin, S. Park, H. Ro, D.-Y. Koh, J. Seol, H. Lee, Spectroscopic Confirmation of Metastable Structure Formation Occurring in Natural Gas Hydrates, Chem. - Asian J. 7 (2012) 2235-2238. doi:10.1002/asia.201200040.

[33] A.H. Nguyen, L.C. Jacobson, V. Molinero, Structure of the Clathrate/Solution Interface and Mechanism of Cross-Nucleation of Clathrate Hydrates, J. Phys. Chem. C. 116 (2012) 19828-19838. doi:10.1021/jp305468s.

[34] D. Le Quang, D. Le Quang, B. Bouillot, J.-M. Herri, P. Glenat, P. Duchet-Suchaux, Experimental procedure and results to measure the composition of gas hydrate, during crystallization and at equilibrium, from $\mathrm{N} 2-\mathrm{CO} 2-\mathrm{CH} 4-\mathrm{C} 2 \mathrm{H} 6-\mathrm{C} 3 \mathrm{H} 8-\mathrm{C} 4 \mathrm{H} 10$ gas mixtures, Fluid Phase Equilibria. (2015). doi:10.1016/j.fluid.2015.10.022.

[35] S. Maghsoodloo Babakhani, B. Bouillot, J. Douzet, S. Ho-Van, J.M. Herri, A new approach of studying mixed gas hydrates involving propane at non-equilibrium conditions and final state: An experimental study and modeling, Chem. Eng. Sci. (2018). doi:10.1016/j.ces.2018.01.017.

[36] B. Bouillot, J.-M. Herri, Framework for clathrate hydrate flash calculations and implications on the crystal structure and final equilibrium of mixed hydrates, Fluid Phase Equilibria. (2015). doi:10.1016/j.fluid.2015.10.023.

[37] G.D. Holder, S.P. Zetts, N. Pradhan, Phase Behavior in Systems Containing Clathrate Hydrates: A Review, Rev. Chem. Eng. 5 (1988) 1-70. doi:10.1515/REVCE.1988.5.1-4.1.

[38] J.-M. Herri, A. Bouchemoua, M. Kwaterski, A. Fezoua, Y. Ouabbas, A. Cameirao, Gas hydrate equilibria for $\mathrm{CO} 2-\mathrm{N} 2$ and $\mathrm{CO} 2-\mathrm{CH} 4$ gas mixtures-Experimental studies and thermodynamic modelling, Fluid Phase Equilibria. 301 (2011) 171-190. doi:10.1016/j.fluid.2010.09.041.

[39] W.I. Wilcox, D.B. Carson, D.L. Katz, Natural Gas Hydrates, Ind. Eng. Chem. 33 (1941) 662-665. doi:10.1021/ie50377a027.

[40] D.L. Katz, Prediction of Conditions for Hydrate Formation in Natural Gases, Trans. AIME. 160 (1945) 140-149. doi:10.2118/945140-G.

[41] G.-J. Chen, T.-M. Guo, A new approach to gas hydrate modelling, Chem. Eng. J. 71 (1998) $145-151$.

[42] G. Zahedi, Z. Karami, H. Yaghoobi, Prediction of hydrate formation temperature by both statistical models and artificial neural network approaches, Energy Convers. Manag. 50 (2009) 2052-2059. doi:10.1016/j.enconman.2009.04.005.

[43] S. Maghsoodloo Babakhani, M. Bahmani, J. Shariati, K. Badr, Y. Balouchi, Comparing the capability of artificial neural network (ANN) and CSMHYD program for predicting of hydrate formation pressure in binary mixtures, J. Pet. Sci. Eng. 136 (2015) 78-87. doi:10.1016/j.petrol.2015.11.002.

[44] S. Shahnazar, N. Hasan, Gas hydrate formation condition: Review on experimental and modeling approaches, Fluid Phase Equilibria. 379 (2014) 72-85. doi:10.1016/j.fluid.2014.07.012.

[45] Y.P. Handa, J.S. Tse, Thermodynamic properties of empty lattices of structure I and structure II clathrate hydrates, J. Phys. Chem. 90 (1986) 5917-5921. doi:10.1021/j100280a092. 
[46] V. McKoy, O. Sinanoğlu, Theory of Dissociation Pressures of Some Gas Hydrates, J. Chem. Phys. 38 (1963) 2946. doi:10.1063/1.1733625.

[47] J.E.D. Sloan, Clathrate Hydrates of Natural Gases, Second Edition, Revised and Expanded, CRC Press, 1998.

[48] J.-M. Herri, E. Chassefière, Carbon dioxide, argon, nitrogen and methane clathrate hydrates: Thermodynamic modelling, investigation of their stability in Martian atmospheric conditions and variability of methane trapping, Planet. Space Sci. 73 (2012) 376-386. doi:10.1016/j.pss.2012.07.028. 